\title{
Technical and Economic Assessment of a High-Quality Syngas Production Process Integrating Oxygen Gasification and Water Electrolysis: The Chinese Case
}

\author{
Guohui Song,* Liang Wang, Ailin Yao, Xiaobo Cui, and Jun Xiao
}

Cite This: ACS Omega 2021, 6, 27851-27864

Read Online

ABSTRACT: Natural gas shortage, waste treatment, and renewable energy utilization and storage are the common issues in China. This research aims to evaluate a simple and reliable biomass and power-tosyngas process for high-quality syngas production integrating oxygen gasification and water electrolysis. The technical and economic evaluations are successively performed based on the simulation data. The single-stage and two-stage gasifiers are integrated and compared. The results show that the process with a two-stage gasifier has advantages in both technical and cost performances over that with a single-stage gasifier. Then, the optimal values of the operating variables are determined by investigating their effects on syngas composition and

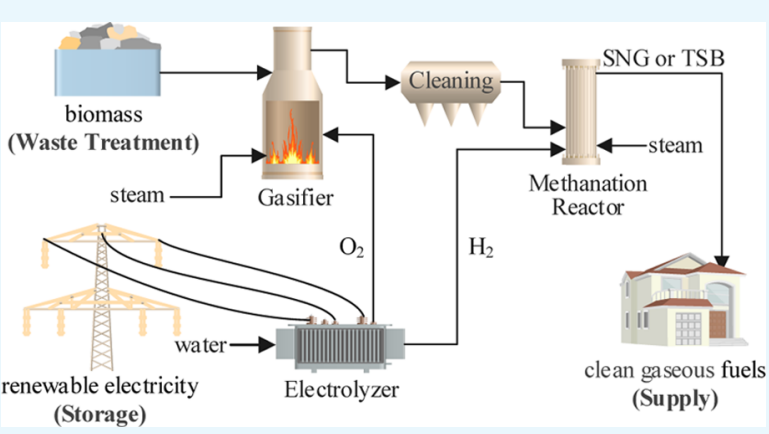
yield and the overall energy and exergy efficiencies. Then, by setting appropriate amounts of water for electrolysis and methanation pressures, the process can generate two typical products: thermochemical synthetic biogas (TSB) or synthetic natural gas (SNG). The overall energy and exergy efficiencies of TSB can reach 74.1 and $69.5 \%$, respectively, while those of SNG can achieve 64.8 and $64.1 \%$, respectively. The unit product cost of TSB is about one third of that of SNG, indicating that TSB makes a profit while SNG results in loss. A sensitivity analysis of the cost indicates that the constraints for TSB are much looser than those for SNG to gain profit. Additionally, this study proposes two indicators to characterize the electricity-storage capacities of biomass and syngas. The indicators show that SNG has big advantages over TSB in the specific capacity of electricity storage, and the capacities of SNG and TSB are approximately 52.0 and 4.7 times of the specific energy density of the lithium-ion battery pack in 2019, respectively. The work could be used as a reference for the countries lacking natural gas and valuable to guide the development of a two-stage gasifier, reduction in equipment cost, and evaluation of electricitystorage performance using biofuels.

\section{INTRODUCTION}

Natural gas is a desirable clean energy resource for economic and social development, but most of the reserves are owned by a few countries. Like many developing countries, China suffers serious natural gas shortages; the rural areas suffer more due to the domestic imbalance in natural gas distribution and consumption. On the demand side, China has a huge demand on substitute natural gas or other high-quality gaseous fuels, especially in winter. Natural gas is a nonrenewable energy source and it is not the sustainable option in the decarbonization race. Emerging technologies that could curb carbon emissions and offer sustainable ways to future are highly expected. On the resource side, China has abundant agriculture residuals, forestry wastes, and household waste that need to be treated in an environmentally friendly manner. ${ }^{1}$ In this context, gaseous biofuels, for example, synthetic natural gas (SNG), have natural advantages in environmental impacts and sustainability. ${ }^{2}$

Traditionally, there are mainly two ways for SNG production from biomass: (i) anaerobic digestion of wet biomass plus biogas upgrading to SNG (including $\mathrm{CO}_{2}$ removal). The anaerobic digestion technology had been commercialized for many years and has several drawbacks such as relatively low yield and energy efficiency, sensitive to reaction temperature and $\mathrm{pH}$, and so forth. ${ }^{3}$ (ii) Conventional SNG process, consisting of steam gasification, gas cleaning, methanation, and $\mathrm{CO}_{2}$ separation. ${ }^{4}$ Although the conventional SNG process has higher energy efficiencies (up to $74 \%$ ), ${ }^{4,5}$ the high-temperature dual-fluidized bed gasifiers for indirect heating of exothermic steam gasification are complex and difficult to design and operate. ${ }^{6}$

One of the goals that researchers keep on studying is to develop better or novel processes of SNG production. The

Received: July 3, 2021

Accepted: September 27, 2021

Published: October 11, 2021 
hydrothermal gasification process $\left(400-450{ }^{\circ} \mathrm{C}, 25-34 \mathrm{MPa}\right)$ was developed to produce SNG from wet biomass (algae and manure) with high conversion efficiency. ${ }^{7,8}$ So far, some crucial technical barriers still need to be settled such as feeding, salt separation, high-pressure safety and erosion, and so forth.,10 The power-to-gas $(\mathrm{PtG})$ concept is one of the recent research hotspots since it converts renewable electrical energy into storable methane via electrolysis and subsequent methanation. $\mathrm{PtG}$ is one of the potential technologies to solve large-scale and long-term energy-storage problems as well as reduce $\mathrm{CO}_{2}$ emissions. By far, there are already dozens of laboratory, pilot, and demo plants, of which most are located in Europe. ${ }^{11}$ To the best of our knowledge, there are only few studies on the biomass-based PtG process in China until now. In 2020, China announced its ambition to peak its carbon emissions by 2030 and achieve carbon neutrality by 2060 . The demands for largescale electrical energy storage are so urgent. It is meaningful to carry out technoeconomic studies on the PtG process under the Chinese scenario to evaluate the competitiveness and promote the applications.

Considering the abovementioned features of demands, resources, and tendencies in China, this study focuses on the technical route of biomass and renewable $\mathrm{PtG}$ integrating oxygen-steam gasification, water electrolysis (WE), and hydrogenation methanation. It is expected to propose a solution to harmonically handle the demands of the clean gaseous biofuel, renewable electricity storage, and waste treatment. As various $\mathrm{PtG}$ process configurations can be designed by integrating different feed stocks or unit technologies, the economic assessment is one of the important concerns. Barbuzza et al. found that in Northern Italy, under the scenario of "electricity at zero cost", the cost of SNG is comparable to the price of the methane for household utilities. $^{12}$ In the scenario of California, it was predicted that the projected cost of SNG by PtG in 2050 would be comparable to but still higher than the cost of conventional natural gas if a high capacity factor could be achieved with low electricity costs together with lower electrolyzer capital cost. ${ }^{13}$ However, a report by Mesfun et al. showed that under the Swedish scenario, the economic performance of the process using molten carbonate electrolysis cells was better than that of the conventional SNG plant if the electricity costs are lower than a certain value. ${ }^{14}$ The minimum selling price of SNG estimated by Menin et al. is more than three times higher than the current subsidized price of grid-quality bSNG produced from waste and byproducts. ${ }^{15}$ Taken together, there were different results or requirements on the cost and competitiveness of SNG with WE. The studies indicate that it is necessary to carry out economic assessments based on the local scenario and the ways which can reduce the production cost and improve the competitiveness are of great significance for this technical route. Based on the characteristics of the process and product, either the gasification technology or the quality of the final product might have considerable potential to get close to these aims.

With the abovementioned technical route, the gasification step plays an important role and the gasification technology should be chosen or developed accordingly. Within the framework of SNG production with WE, Gassner and Maréchal compared the performances of directly and indirectly heated gasification systems, as well as the fast internally circulating fluidized bed and circulating fluidized bed. ${ }^{16,17}$ However, the optimization or development of the gasifier was not involved. Barbuzza et al. analyzed a PtG system in which hydrogen obtained via electrolysis was used for wood hydrogasification. ${ }^{12}$ Recent studies revealed that the staged gasification has some advantages such as low tar content, higher energy efficiency, and so forth. ${ }^{18,19}$ It is worth investigating the process integrating staged gasification.

Judging from the functions of the methanation reaction of $\mathrm{CO}$ and $\mathrm{CO}_{2}$, the process can theoretically produce highquality syngas that has equivalent quality to biogas. ${ }^{20}$ Here, the syngas is named thermochemical synthetic biogas (TSB) to distinguish the thermochemical technique from anaerobic digestion. The product in related previous studies is SNG, aiming to eject it into a well-developed gas grid. ${ }^{11,21}$ In China, biogas without $\mathrm{CO}_{2}$ removal is widely used for cooking and heating in many places. ${ }^{22}$ Accelerated by the "rural revitalization strategy" and rural "coal to gas" policies, the development of biogas has become increasingly popular, and China's energy sector targets achieving an annual yield of 20 billion $\mathrm{m}^{3}$ of biomethane by $2030 .^{22}$ TSB might have considerable potential by directly using as fuel. Then, the feasibility and competitiveness of TSB need to be studied as an alternative option of energy carrier.

Motivated by the abovementioned analysis, the objective of this work is to study a biomass and renewable power-to-syngas process integrating biomass gasification, WE, and hydrogenation methanation. Two types of products, SNG and TSB, are considered and compared. The process is modeled using Aspen Plus software. The composition and yield, energy and exergy efficiencies, electricity-storage capacity, and unit product cost are investigated as the performance indicators. The work would be valuable to guide the development of the gasifier, reduction in equipment cost, and selection of the rational gas quality. The results can be used as references for the areas in other countries lacking natural gas.

\section{PROCESS SIMULATION AND ASSESSMENT METHODOLOGIES}

2.1. Process Description. Considering the suitable scale of biomass utilization factory in China, ${ }^{23}$ the mass flow rate of biomass was set to $25 \mathrm{t} / \mathrm{h}$ as the base value. Wheat straw is chosen as the feedstock as it is an abundant, geographically ubiquitous, and cheap agriculture waste. Table 1 lists the composition (on air-dried basis, ad), lower heating value (LHV), and specific chemical exergy (SCE) of the feedstock. The SCE is calculated based on the composition data. ${ }^{24}$

Table 1. Composition, LHV, and SCE of Wheat Straw

\begin{tabular}{|c|c|c|}
\hline property & & value \\
\hline \multicolumn{3}{|c|}{ composition (wt \%, ad) } \\
\hline \multirow[t]{4}{*}{ proximate analysis } & $\mathrm{M}$ & 3.3 \\
\hline & FC & 18.73 \\
\hline & $\mathrm{VM}$ & 71.59 \\
\hline & A & 6.38 \\
\hline \multirow[t]{5}{*}{ ultimate analysis } & $\mathrm{C}$ & 43 \\
\hline & $\mathrm{H}$ & 5.36 \\
\hline & $\mathrm{N}$ & 0.63 \\
\hline & S & 0.22 \\
\hline & $\mathrm{O}$ & 41.11 \\
\hline LHV $(\mathrm{kJ} / \mathrm{kg}, \mathrm{ad})$ & & \\
\hline SCE (kJ/kg, ad) & & \\
\hline
\end{tabular}




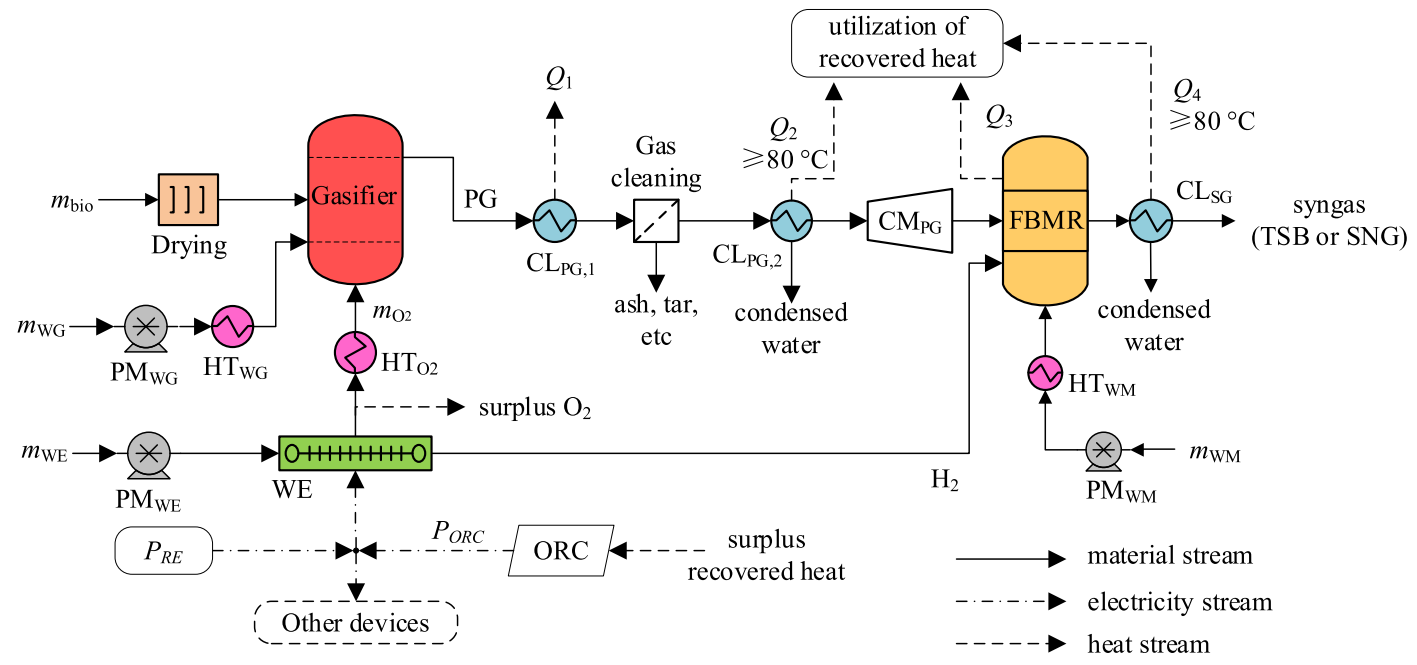

Figure 1. Process flow sheet of the biomass and renewable power-to-syngas process integrating oxygen gasification and WE.

Based on the abovementioned scenario, the plant should be simple, easy, and reliable to construct, operate, and maintain. The biomass and renewable power-to-syngas process is designed and illustrated in Figure 1. It mainly consists of (i) a gasification system including a water pump $\left(\mathrm{PM}_{\mathrm{G}}\right)$ and heaters for steam generation $\left(\mathrm{HT}_{\mathrm{G}}\right)$ and $\mathrm{O}_{2}$ preheating $\left(\mathrm{HT}_{\mathrm{O}_{2}}\right)$; (ii) a WE system; (iii) a producer gas cleaning and cooling (PGCC) system integrating hot gas cleaning devices and several coolers for producer gas $(\mathrm{PG})\left(\mathrm{CL}_{\mathrm{PG} 1}\right.$ and $\left.\mathrm{CL}_{\mathrm{PG} 2}\right)$; and (iv) a methanation synthesis system including a compressor $\left(\mathrm{CM}_{\mathrm{PG}}\right)$, a water pump $\left(\mathrm{PM}_{\mathrm{M}}\right)$, and heater $\left(\mathrm{HT}_{\mathrm{M}}\right)$ and a set of coolers for syngas $\left(\mathrm{CL}_{\mathrm{SG}}\right)$. Other auxiliary devices for heat utilization and organic Rankine cycle (ORC) are integrated in this study but not shown in detail. The $\mathrm{CO}_{2}$ separation is not integrated as a post-upgrading unit since one of the goals is to produce SNG by a simple process. The $\mathrm{CO}_{2}$ separation will obviously increase the complexity of the process and the production cost (about 10-15\%) based on the existing biogas upgrading projects. ${ }^{25}$

2.1.1. Gasification System. Gasification is the primary step for high-quality syngas production. The feedstock $\left(m_{\text {bio }}\right)$ is first dried by low-temperature heat recovered within this process. The dried biomass is converted into PG, tars, residual char, and ash by thermochemical gasification using oxygen and steam as gasifying agents. Prior to gasification, the water for gasification $\left(m_{\mathrm{WG}}\right)$ and the oxygen $\left(m_{\mathrm{O}_{2}}\right)$ are preheated to 200 ${ }^{\circ} \mathrm{C}$ by the heaters $\mathrm{HT}_{\mathrm{G}}$ and $\mathrm{HT}_{\mathrm{O}_{2}}$, respectively. The PG has high contents of $\mathrm{H}_{2}$ and $\mathrm{CO}$, and there are risks of explosion and toxicity hazards. In this study, the gasifier is assumed to be operated at atmospheric pressure and over the gasification temperature $\left(T_{\mathrm{G}}\right)$ range of $800-1000{ }^{\circ} \mathrm{C}$ (Table 2$)$.

Table 2. Model Blocks and Operation Parameters of the Major Devices (Underline: Base Value)

\begin{tabular}{lll}
\multicolumn{1}{c}{ device } & model & \multicolumn{1}{c}{ parameter(s) } \\
pyrolysis & Ryield & $350{ }^{\circ} \mathrm{C}, 0.1 \mathrm{MPa}$ \\
gasification & RGibbs & $T_{\mathrm{G}}=800-1000{ }^{\circ} \mathrm{C} ; 0.1 \mathrm{MPa} ; \mathrm{S} / \mathrm{B}=\underline{0.4-1 ; \mathrm{SR}=}$ \\
& & $\underline{0.107}-0.217$ \\
WE & RStoic & $80{ }^{\circ} \mathrm{C} ; \eta_{\mathrm{WE}}=65-90 \%, 80 \%$ \\
FBMR & RGibbs & $300{ }^{\circ} \mathrm{C} ; p_{\mathrm{M}}=\underline{5}-70 \mathrm{bar} ; \mathrm{WR}=\underline{1-6}$
\end{tabular}

A gasifier is the most crucial equipment in this process. With regard to steam gasification, the gasifier in the form of fluidized bed reactors, especially internally circulating fluidized bed or dual fluidized bed system, is a popular solution. ${ }^{16,17,26}$ Since the gasification is an endothermic process, indirect heat supply to gasification is prerequisite to avoid the dilution of PG by nitrogen. When oxygen gasification is involved, a single fluidized bed gasifier or fixed bed gasifier is available because the oxygen gasification is an autothermic process. Additionally, the emerging staged-gasification could be a substitute and even better option. ${ }^{19}$ A pilot-scale two-stage gasifier had been successfully applied in oxygen-enriched air gasification. ${ }^{18}$ Thus, both single-stage and two-stage gasifiers are studied and compared.

Figure $2 \mathrm{a}$ shows that the conventional single-stage gasifier employs a single fluidized bed or fixed bed as the gasifier. In

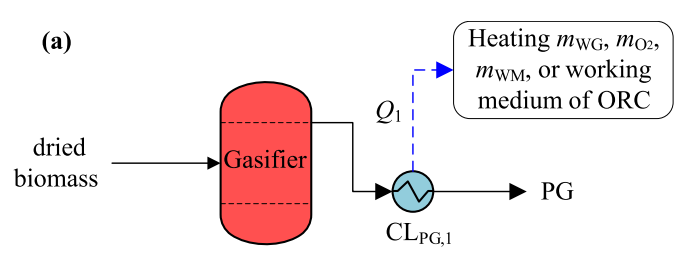

single-stage gasifier

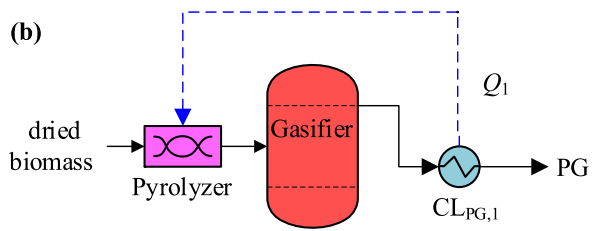

two-stage gasifier

Figure 2. Configurations of (a) single-stage and (b) two-stage gasifiers.

this case, there is no pyrolyzer and all the pyrolysis and gasification reactions take place in one reactor. All heat recovered from PG $\left(Q_{1}\right.$ and $\left.Q_{2}\right)$ is used to heat the streams such as water, oxygen, and ORC working medium except dried biomass. 
Figure $2 \mathrm{~b}$ shows that the two-stage gasifier consists of reactors, which are physically separated. The first-stage reactor (pyrolyzer) is operated at about $350{ }^{\circ} \mathrm{C}$ and plays the role of the physical zone of heating and pyrolysis to some extent. The second-stage reactor (gasifier) is the physical zone of gasification of the mixtures produced in the first-stage reactor. In this case, the heat recovered by $\mathrm{CL}_{\mathrm{SG} 1}\left(Q_{1}\right)$ is transferred to the first stage to heat the dried biomass.

2.1.2. WE System. The WE system converts water $\left(m_{\mathrm{WE}}\right)$ into highly pure $\mathrm{O}_{2}$ and $\mathrm{H}_{2}$ by renewable electricity. The exact amount of $\mathrm{O}_{2}$ is piped into the gasifier to operate the gasifier at the expected $T_{\mathrm{G}}$. The surplus $\mathrm{O}_{2}$, if there exists, is sold to outside users. By comparison, all the $\mathrm{H}_{2}$ is piped into the methanation reactor. Currently, the operating temperature of alkaline electrolysis cells (AECs) and proton exchange membrane electrolysis cells (PEMECs) varies from 50 to 80 ${ }^{\circ} \mathrm{C}$, while that of solid oxide electrolysis cells (SOECs) varies from 650 to $1000{ }^{\circ} \mathrm{C}$. The operating pressures of AEC and SOEC do not exceed 30 bar, while that of PEMECs can be up to 200 bar. $^{27}$ The efficiency of the electrolysis system ranges from 62 to $90 \%$ based on $\mathrm{HHV}_{\mathrm{H}_{2}} \cdot{ }^{28}$

2.1.3. PGCC System. A series of heat exchangers are arranged in the PGCC and recover the heat of PG from gasification at required temperatures. First, high-temperature PG generated is first cooled to about $300{ }^{\circ} \mathrm{C}$ using the cooler $\mathrm{CL}_{\mathrm{PG}, 1}$ and simultaneously plenty of heat $\left(Q_{1}\right)$ is recovered. For a two-stage gasifier, $Q_{1}$ is used to heat dried biomass in the first-stage reactor; while for the single-stage gasifier, $Q_{1}$ is used to heat other streams except dried biomass, as shown in Figure 2a.

The PG is purified using the hot gas cleaning technology, which integrates particle removal with candle filters or electrostatic precipitators, catalytic cracking of the tars, and high-temperature adsorption of other contaminants. Subsequently, the hot $\mathrm{PG}$ is cooled to $40{ }^{\circ} \mathrm{C}$ using a set of coolers $\left(\mathrm{CL}_{\mathrm{PG}, 2}\right)$ and partial vapor in $\mathrm{PG}$ is condensed and removed. In this step, the heat is recovered from PG with temperature above $80{ }^{\circ} \mathrm{C}$.

2.1.4. Methanation Synthesis System. In the methanation reactor, $\mathrm{CO}$ and/or $\mathrm{CO}_{2}$ with $\mathrm{H}_{2}$ are converted into $\mathrm{CH}_{4}$ and $\mathrm{H}_{2} \mathrm{O}$ depending on the methanation reactions and water-gas shift reaction (WGSR) ${ }^{20}$

$$
\begin{aligned}
& \mathrm{CO}+3 \mathrm{H}_{2} \leftrightarrow \mathrm{CH}_{4}+\mathrm{H}_{2} \mathrm{O} \quad \Delta H=-206 \mathrm{~kJ} / \mathrm{mol} \\
& \mathrm{CO}_{2}+4 \mathrm{H}_{2} \leftrightarrow \mathrm{CH}_{4}+2 \mathrm{H}_{2} \mathrm{O} \quad \Delta H=-165 \mathrm{~kJ} / \mathrm{mol} \\
& \mathrm{CO}+\mathrm{H}_{2} \stackrel{\mathrm{O}}{\mathrm{H}_{2}}+\mathrm{CO}_{2} \quad \Delta H=-41 \mathrm{~kJ} / \mathrm{mol}
\end{aligned}
$$

Besides, carbon formation may also occur ${ }^{20}$

$$
\begin{aligned}
2 \mathrm{CO}(\mathrm{g}) \leftrightarrow \mathrm{CO}_{2}(\mathrm{~g})+\mathrm{C}(\mathrm{s}) \quad \Delta H=172 \mathrm{~kJ} / \mathrm{mol} \\
\mathrm{CO}(\mathrm{g})+\mathrm{H}_{2}(\mathrm{~g}) \leftrightarrow \mathrm{C}(\mathrm{s})+\mathrm{H}_{2} \mathrm{O}(\mathrm{g}) \\
\Delta H=131 \mathrm{~kJ} / \mathrm{mol}
\end{aligned}
$$

Thus, a certain amount of water $\left(m_{\mathrm{WM}}\right)$ is added into the methanation reactor to suppress carbon formation. Prior to methanation, the water for methanation $\left(w_{\mathrm{M}}\right)$ is heated to 200 ${ }^{\circ} \mathrm{C}$.

The stoichiometric coefficients of RR1 and RR2 allow determining the amount of $\mathrm{H}_{2}$ that is needed to completely reform $\mathrm{CO}$ and $\mathrm{CO}_{2}$ into $\mathrm{CH}_{4}$. Here, the stoichiometric number $(\mathrm{SN})$ of the incoming gas stream is defined in order to characterize the achievable methane yield. The amount of $\mathrm{H}_{2}$ generated by WE can vary extensively. Two SNs are defined to represent the characteristics of the mixed gas ( $P G$ and $\mathrm{H}_{2}$ streams), that is

$$
\begin{aligned}
& \mathrm{SN}_{1}=\frac{m_{\mathrm{H}_{2}, \mathrm{PG}}+m_{\mathrm{H}_{2}, \mathrm{WE}}}{3 \cdot m_{\mathrm{CO}, \mathrm{PG}}} \\
& \mathrm{SN}_{2} \frac{m_{\mathrm{H}_{2}, \mathrm{PG}}+m_{\mathrm{H}_{2}, \mathrm{WE}}}{3 \cdot m_{\mathrm{CO}, \mathrm{PG}}+4 \cdot m_{\mathrm{CO}_{2}, \mathrm{PG}}}
\end{aligned}
$$

where $m_{\mathrm{H}_{2}, \mathrm{PG}}$ and $m_{\mathrm{H}_{2}, \mathrm{WE}}$ are the molar flow rates of $\mathrm{H}_{2}$ in PG and that generated by $\mathrm{WE}$, respectively. $m_{\mathrm{CO}, \mathrm{PG}}$ and $m_{\mathrm{CO}_{2}, \mathrm{WE}}$ are the molar flow rates of $\mathrm{CO}$ and $\mathrm{CO}_{2}$ in $\mathrm{PG}$, respectively. When $\mathrm{SN}_{1}$ is less than 1, WGSR plays an important role in syngas composition. To obtain a highly pure methane stream, $\mathrm{SN}_{2}$ should be close to unity.

Methane synthesis of a $\mathrm{H}_{2} / \mathrm{CO} / \mathrm{CO}_{2}$ mixture is highly exothermic and its reactor design is critical with regard to temperature control. The single isothermal once-through fluidized bed methanation reactor (FBMR) is adopted in this process configuration, which allows for simultaneous methanation and WGSRs. ${ }^{29}$ Lower methanation temperature favors the thermodynamic performances of the process, and the FBMR is assumed to operate constantly at $300{ }^{\circ} \mathrm{C}$ and over the methanation pressure $\left(p_{\mathrm{M}}\right)$ range of 5-70 bar (Table 2$)$. The heat released by exothermic reactions $\left(Q_{3}\right)$ is also recovered to heat water, oxygen, or ORC working medium. Finally, the syngas, the output of methanation reactions, is cooled to the required temperature using the cooler $\mathrm{CM}_{\mathrm{SG}}$, and a drier may be installed as needed. It also removes most vapor in syngas and recovers plenty of sensible heat $\left(Q_{4}\right)$ with temperature above $80{ }^{\circ} \mathrm{C}$.

2.1.5. Energy Integration. There are mainly four heat streams $\left(Q_{1}-Q_{4}\right)$ that can be revered and utilized. The heat energies, either $Q_{1}-Q_{4}$ of the process with a single-stage gasifier or $Q_{2}-Q_{4}$ of the process with a two-stage gasifier, are first used to preheat the gasifying agents $\left(m_{\mathrm{WG}}\right.$ and $\left.m_{\mathrm{O}_{2}}\right)$ and water for methanation synthesis $\left(m_{\mathrm{WM}}\right)$. The surplus recovered heat energies are used to generate electricity using the ORC technology to compensate the electricity of the whole process. Finally, the gap between the total power consumption $\left(P_{\mathrm{T}}\right)$ and power generated by ORC $\left(P_{\text {ORC }}\right)$ is filled by the external renewable power $\left(P_{\mathrm{RE}}\right)$.

2.2. Process Simulation. The modeling of the process is based on our relevant previous works including conventional SNG process, ${ }^{26}$ chemical looping gasification, ${ }^{30}$ and staged gasification, ${ }^{19}$ where we had described the simulations of the steam gasification, PGCC, and methanation in detail. Briefly, the models for reactors are listed in Table 2. Based on the Aspen Plus platform, the PR-BM method is applied as the base property method and STEAM-TA is employed as the freewater method. The gasifier is simulated by resolving into pyrolysis and gasification processes, which are simulated using RYield and RGibbs models, respectively. The RGibbs model is restricted by chemical equilibrium with the temperature approach. $\xi$ It is assumed that all reactors are operated under a steady state, and residence times are long enough for the reactions to reach chemical equilibrium. The influences of particle sizes of feedstock are not considered. $\xi$ The reactor 
temperature and pressure are taken as uniform, and the pressure loss of the system is set to be $3 \mathrm{kPa}$. Ash in biomass does not participate in any chemical reactions. The carbon conversion efficiency of the feedstock is $99 \%$. The heat loss of gasification is assumed to be $3 \%$ of the input energy of biomass (based on LHV). A design-Spec is set to calculate the amount of water for electrolysis $\left(m_{\mathrm{WE}}\right)$ at a given $T_{\mathrm{G}}$ based on energy conservation. The simulation of oxygen-steam gasification is verified based on experimental data at the pilot scale reported by Barisano et $\mathrm{al}^{31}$ Table $\mathrm{S} 1$ indicates that the differences between simulation values and average experimental vales of the major components (in vol \%) are less than 4 percentage points.

With respect to PGCC, besides Heater models for simulation of coolers, a Sep model is applied to simulate the separation procedure in PGCC. A pressure drop of $5 \mathrm{kPa}$ in PGCC is assumed to estimate the energy and exergy losses. ${ }^{26}$ To simplify the simulation and protect the downstream compressor, the separation efficiency for ash and char is assumed to be $100 \%$.

The FBMR is simulated based on the RGibbs model and both phase and chemical equilibriums are calculated. The pressure drop in the reactor is assumed to be $2 \mathrm{kPa}$. The verification of the simulation of the methanation at $p_{M}$ of 60 bar is verified using composition data of PG and SNG reported by Saric et al. ${ }^{32}$ Table S2 indicates that all the simulation values are within the ranges of the reference values.

The model blocks and operation parameters of other auxiliary devices are listed in Table S3. Heat exchangers are modeled with a pressure drop of $0.5 \mathrm{kPa}$ and an energy efficiency of $95 \%$. Pumps are operated with an isentropic efficiency of $85 \%$ and a mechanical efficiency of $98 \%$. The multistage compressor is simulated using the polytropic model using the ASME method. The net efficiency of ORC is set as $25 \%$

2.3. Energy and Exergy Analyses. To evaluate the technical competitiveness of the process, the following parameters are focused on composition, yield, LHV, and SCE of the syngas and overall energy and exergy efficiencies of the process

$$
\mathrm{LHV}_{\mathrm{SG}}=802.6 \cdot \mathrm{CH}_{4}+241.81 \cdot \mathrm{H}_{2}+282.98 \cdot \mathrm{CO}(\mathrm{kJ} / \mathrm{mol})
$$

$$
\mathrm{SCE}_{\mathrm{SG}}=831.69 \cdot \mathrm{CH}_{4}+236.1 \cdot \mathrm{H}_{2}+275.06 \cdot \mathrm{CO}(\mathrm{kJ} / \mathrm{mol})
$$

$$
\begin{aligned}
& \eta_{\mathrm{en}}=\frac{\mathrm{ml}_{\mathrm{SG}} \cdot \mathrm{LHV}_{\mathrm{SG}}}{\mathrm{En}_{\mathrm{bio}}+3.6 P_{\mathrm{RE}}} \times 100 \% \\
& \eta_{\mathrm{ex}}=\frac{\mathrm{ml}_{\mathrm{SG}} \cdot \mathrm{SCE}_{\mathrm{SG}}}{\mathrm{Ex}_{\mathrm{bio}}+3.6 P_{\mathrm{RE}}} \times 100 \%
\end{aligned}
$$

where $\mathrm{ml}_{\mathrm{SG}}$ is the mole flow rate of syngas, in $\mathrm{kmol} / \mathrm{h}$ and $\mathrm{En}_{\mathrm{bio}}$ and $\mathrm{Ex}_{\mathrm{bio}}$ are the energy and exergy flow rate of biomass, respectively, in $\mathrm{MJ} / \mathrm{h} . P_{\mathrm{RE}}$ is the electrical power supplied by external renewable sources, in $\mathrm{kW}$, which is equal to the total electrical power consumed by the process $\left(P_{\mathrm{T}}\right)$ minus the power generated by the surplus recovered heat using ORC (P $\left.P_{\text {ORC }}\right)$.

The following variables are studied: $T_{\mathrm{G}}$, stoichiometric ratio of $\mathrm{O}_{2}$ (SR), steam-to-biomass ratio $(\mathrm{S} / \mathrm{B})$, water ratio for electrolysis $(\mathrm{WR})$, electrolysis efficiency $\left(\eta_{\mathrm{WE}}\right)$, and $p_{\mathrm{M}}$. The $\mathrm{SR}$ is defined as the mole ratio between the amount of actual oxygen fed in and the stoichiometric amount of oxygen required for gasification. The $\mathrm{S} / \mathrm{B}$ is defined as the mass flow rate of steam fed to the gasifier divided by the mass flow rate of biomass (as-received basis). The WR is defined as given below:

$$
\mathrm{WR}=\frac{m_{\mathrm{WE}}}{m_{\mathrm{WE}, \mathrm{G}}}
$$

where $m_{\mathrm{WE}}$ is the actual amount of water for electrolysis to generate $\mathrm{H}_{2}$ and $\mathrm{O}_{2}$ and $m_{\mathrm{WE}, \mathrm{G}}$ is the amount of water for electrolysis corresponding to the amount of oxygen that just satisfies the demand of biomass gasification under the given conditions. When WR is greater than 1 , the surplus $\mathrm{O}_{2}$ is sold to external users, while all $\mathrm{H}_{2}$ is added into the methanation reactor. The ranges and base values (marked by underline) of the key variables are summarized in Table 2.

2.4. Economic Assessment. The economic assessment aims for determining costs of production for typical syngas and comparing these process configurations. To achieve this goal, this study employs the cost model (Table S4) including total capital investment (TCI), total production cost (TPC), and unit product cost (UPC). ${ }^{33,34}$ TCI includes fixed capital investment (FCI) and working capital (WC). Also, FCI consists of indirect and direct investments that have to be estimated first. For this purpose, all main equipment components have to be designed according to the mass and energy flows and their equipment costs have to be gathered.

2.4.1. Equipment Cost and Fixed Capital Investment. Among the components, equipment costs are the key data to estimate TCI, which are expressed as given below

$$
\mathrm{EC}_{2019}=\mathrm{EC}_{\mathrm{ref}} \times\left(\frac{\mathrm{PC}}{\mathrm{PC}_{\mathrm{ref}}}\right)^{n} \times \frac{\mathrm{CEPCI}_{2019}}{\mathrm{CEPCI}_{\mathrm{ref}}}
$$

where $\mathrm{PC}_{\mathrm{ref}}$ and $\mathrm{EC}_{\mathrm{ref}}$ are the production capacity and equipment cost of the reference case, respectively. PC and $\mathrm{EC}_{2019}$ are the production capacity and equipment cost of the planning plant in 2019, respectively. $n$ refers to the scale exponent and CEPCI refers to the chemical engineering plant cost index, which is developed to refresh $\mathrm{EC}$ from a past date to present time. Based on the values of $\mathrm{PC}_{\mathrm{ref}}, \mathrm{EC}_{\mathrm{ref}}, \mathrm{CEPCI}_{\mathrm{ref}}$, and $n$ in Table S5, ${ }^{34,35}$ the equipment costs of the devices are calculated using the simulated technical data. The systems of gasifier, methanation, and $\mathrm{WE}$ include both the reactors and pumps. Based on the equipment cost, the other investment indicators are estimated based on the TCI model presented in Table S4.

2.4.2. Total Production Cost. Table S6 presents the TPC structure on an annual basis. ${ }^{34}$ It primarily consists of raw material, utilities, maintenance and operating, depreciation, plant overhead cost, administrative cost, distribution, and selling cost. In China, the cost of agriculture and forest residuals $\left(C_{\text {bio }}\right)$ generally varies from 100 to $450 \mathrm{CNY} / \mathrm{t}$. When household waste is processed as feedstock, $C_{\text {bio }}$ can be negative values with subsidies (as low as $-60 \mathrm{CNY} / \mathrm{t}$ ). As one of the goals of this process is to store surplus renewable electricity, considering the grid purchase prices of solar and wind powers in different areas in China, we assume the electricity cost $\left(\mathrm{C}_{\mathrm{EL}}\right)$ varies from 0.1 to $0.45 \mathrm{CNY} / \mathrm{kWh}$ with a base value of 0.3 $\mathrm{CNY} / \mathrm{kWh}$. Other costs such as catalysis, water, and operating laborer are listed in Table S6. Additionally, under conditions of $4 \%$ salvage value and 20 years lifetime, depreciation is calculated according to the straight line method. 
2.4.3. Unit Product Cost. UPC is calculated based on TPC and annual yield of the product. It should be noted that in the case of SNG, plenty of byproduct $\mathrm{O}_{2}$ is generated by WE. The $\mathrm{O}_{2}$ is assumed to be sold at the original state. The pressurization and liquefaction are carried out by external users. The cost of oxygen continuously reduced in recent years. ${ }^{36}$ In 2021, oxygen cost of a newly built project using vacuum pressure swing adsorption in Hunan province, China, is as low as $0.2 \mathrm{CNY} / \mathrm{m}^{3}$, which is adopted as the selling price in this study.

\section{PROCESS PERFORMANCES}

3.1. Comparison between Single-Stage and TwoStage Gasifiers. In actual operation, the gasification temperature is determined by the stoichiometric ratio. In order to demonstrate the differences between single-stage and two-stage gasifiers, the SR value is calculated in reverse by the energy conservation at the given $T_{G}$. The result in Figure 3 shows that

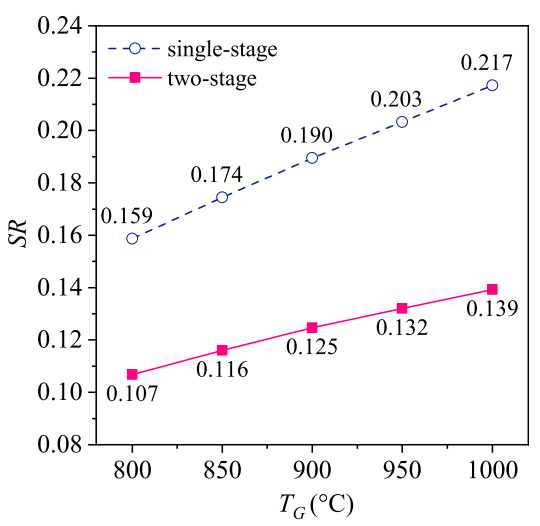

Figure 3. Relation between $S R$ and $T_{\mathrm{G}}$.

SR proportionally increases with $T_{\mathrm{G}}$. As the oxygen-steam gasification is an autothermic process, more heat is required at higher $T_{G}$, and the adjustment measure is to increase the amount of oxygen to combust more biomass and release more heat. The SR for single-stage gasification varies from 0.159 to 0.217 , which is consistent with the data in previous studies. ${ }^{38,39}$ This reveals that the gasification simulation in this work is correct and reliable. Figure 3 also shows that the SR of a singlestage gasifier is about 1.5 times of that of a two-stage gasifier at the same $T_{\mathrm{G}}$ over the studied range. When $\eta_{\mathrm{WE}}$ is a constant and no surplus $\mathrm{O}_{2}$ is generated $(\mathrm{WR}=1)$, the electrical power consumed by WE $\left(p_{\mathrm{WE}}\right)$ is proportional to the flow rate of $\mathrm{O}_{2}$. Thus, the $p_{\mathrm{WE}}$ for the operation of a single-stage gasifier is about 1.5 times of that of a two-stage gasifier, which is also confirmed by the case presented in Figure 4.

Table 3 presents the compositions of PG and syngas, as well as the energy and exergy efficiencies of the processes with single-stage and two-stage gasifiers. Although there is a big difference in SR, the PG composition with a single-stage gasifier is similar to that with a two-stage gasifier. The differences in syngas composition and yield with the two types of gasification can be ignored due to the adjustment by methanation reactions and so are the differences in LHV and SCE of syngas, which are determined by the composition.

Table 3 shows that at a $T_{\mathrm{G}}$ of $800{ }^{\circ} \mathrm{C}, \eta_{\mathrm{en}}$ and $\eta_{\mathrm{ex}}$ with a single-stage gasifier are about 6 and 5 percentage points lower than those with a two-stage gasifier, respectively. The $Q_{1}$ accounts for approximately $9 \%$ of the total energy input of

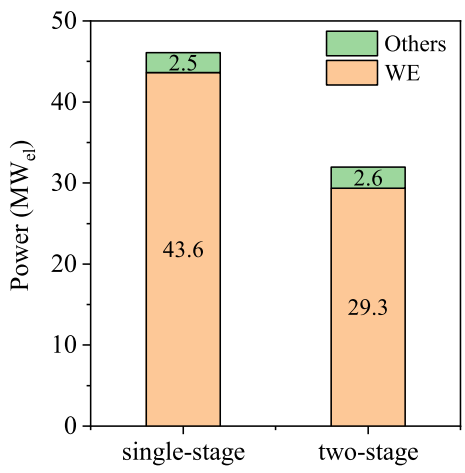

Figure 4. Comparison of power consumptions between the processes with single-stage and two-stage gasifiers.

Table 3. Technical Performances with Single-Stage and Two-Stage Gasifiers

\begin{tabular}{lcl}
\multicolumn{1}{c}{ parameter } & single-stage & two-stage \\
& PG Composition $($ vol \%, db) & \\
$\mathrm{CH}_{4}$ & 9.9 & 9.3 \\
$\mathrm{H}_{2}$ & 31.3 & 35.4 \\
$\mathrm{CO}$ & 34.1 & 36.4 \\
$\mathrm{CO}_{2}$ & 24.2 & 18.4 \\
& Syngas Composition $(\mathrm{vol} \%, \mathrm{db})$ & \\
$\mathrm{CH}_{4}$ & 47.5 & 47.6 \\
$\mathrm{H}_{2}$ & 3.6 & 3.4 \\
$\mathrm{CO}_{\mathrm{CO}}$ & 0.03 & 0.03 \\
$\mathrm{CO}_{2}\left(\mathrm{Nm}{ }^{3} / \mathrm{kg}\right)$ & 48.1 & 48.1 \\
$\eta_{\mathrm{en}}(\%)$ & 0.839 & 0.838 \\
$\eta_{\mathrm{ex}}(\%)$ & 68.4 & 74.1 \\
& 64.6 & 69.5
\end{tabular}

the feedstock. Thus, the oxygen required by a single-stage gasifier is much more than that by a two-stage gasifier, which is represented by the values of SR (Figure 3). Figure 4 further indicates that most electricity $(>90 \%)$ is consumed by the WE system. As WE has a significant energy loss $(20 \%$ in the basic scenario), the $\eta_{\mathrm{en}}$ and $\eta_{\mathrm{ex}}$ with a single-stage gasifier are obviously lower than those with a two-stage gasifier, respectively. Thus, the following study is mainly carried out based on a two-stage gasifier.

3.2. Effects of $T_{\mathrm{G}}$. The effects of $T_{\mathrm{G}}$ on PG composition had been investigated by previous studies and the variations had been figured out. ${ }^{39}$ Then, only properties of syngas are focused on in the following analysis. Table 4 indicates that for the process integrating oxygen gasification and $\mathrm{WE}$, when $T_{\mathrm{G}}$ rises from 800 to $1000{ }^{\circ} \mathrm{C}, \mathrm{SN}_{1}$ decreases very slightly while $\mathrm{SN}_{2}$ increases visibly. Even so, the composition and yield of

Table 4. Properties of PG and Syngas Over the $T_{\mathrm{G}}$ Range of 800-1000 ${ }^{\circ} \mathrm{C}$

\begin{tabular}{|c|c|c|c|c|c|}
\hline$T_{\mathrm{G}}\left({ }^{\circ} \mathrm{C}\right)$ & 800 & 850 & 900 & 950 & 1000 \\
\hline $\mathrm{SN}_{1}$ & 0.519 & 0.518 & 0.518 & 0.517 & 0.517 \\
\hline $\mathrm{SN}_{2}$ & 0.310 & 0.326 & 0.341 & 0.352 & 0.36 \\
\hline \multicolumn{6}{|c|}{ Syngas Composition (vol \%, db) } \\
\hline $\mathrm{CH}_{4}$ & 47.6 & 47.6 & 47.6 & 47.6 & 47.6 \\
\hline $\mathrm{H}_{2}$ & 3.4 & 3.5 & 3.5 & 3.5 & 3.4 \\
\hline $\mathrm{CO}$ & 0.03 & 0.03 & 0.03 & 0.03 & 0.03 \\
\hline $\mathrm{CO}_{2}$ & 48.1 & 48.1 & 48.1 & 48.1 & 48.1 \\
\hline$Y_{S G}\left(\mathrm{Nm}^{3} / \mathrm{kg}\right)$ & 0.838 & 0.838 & 0.838 & 0.839 & 0.83 \\
\hline
\end{tabular}


syngas (TSB) vary very little with $T_{\mathrm{G}}$, that is, the results driven by the methanation-related reactions $(\mathrm{R} 1-\mathrm{R} 3)$. This result is beneficial to the composition control in operation. As $T_{\mathrm{G}}$ is a crucial operating parameter to tar reduction, the $T_{\mathrm{G}}$ in such a process can be appropriately improved, which causes little variation in syngas composition.

The combination of Tables 3 and 4 shows that the syngas has very lower $\mathrm{CO}$ content $(<1$ vol \%) and medium $\mathrm{HHV}$, which meets the requirements of city gas by the Chinese technical standard. ${ }^{40}$ Also, it is interesting that the compositions of syngas with a WR of 1 at various $T_{\mathrm{G}}$ are similar to that of biogas ${ }^{41}$ or crude SNG. ${ }^{42}$ Therefore, the syngas is named TSB, that is, TSB, which can be directly used without upgrading to SNG in rural areas.

Additionally, Figure 5 shows that both $\eta_{\text {en }}$ and $\eta_{\text {ex }}$ gradually reduce by 4 percentage points with the increase in $T_{G}$ from

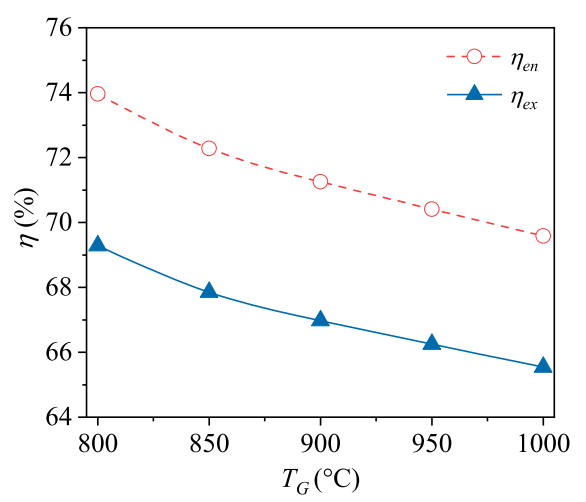

Figure 5. Variations of $\eta_{\mathrm{en}}$ and $\eta_{\mathrm{ex}}$ with $T_{\mathrm{G}}$.

800 to $1000{ }^{\circ} \mathrm{C}$. This can be explained by the variation in electricity consumption. The SR proportionally increases with $T_{G}$, which causes increases in the amount of water for electrolysis, electrical power, and energy loss during electrolysis. This finally results in the decreases in energy and exergy efficiencies. In brief, the abovementioned variations demonstrate that lower gasification temperature is favorable on the premise that the requirements of gasification are satisfied, such as carbon conversion, tar content, and so forth.

3.3. Effects of S/B. S/B has significant influence on $P G$ composition, which had been sufficiently invested by previous studies. ${ }^{43,44}$ This study only focuses on the effects on syngas. The results indicate that $\mathrm{S} / \mathrm{B}$ has little impact on both composition and yield of the syngas due to the function of hydrogenation methanation. Figure 6 shows that the $\eta_{\text {en }}$ and

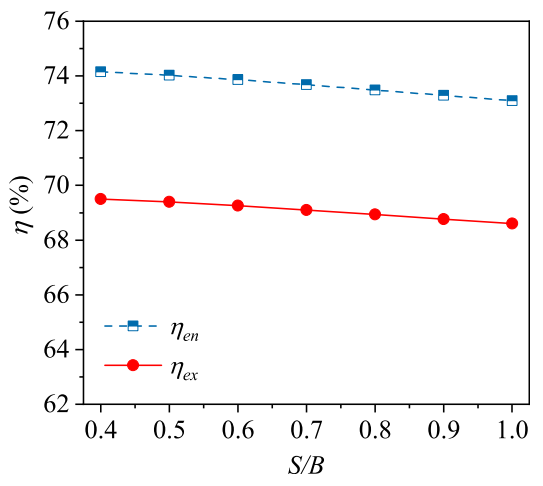

Figure 6. Variations of $\eta_{\mathrm{en}}$ and $\eta_{\mathrm{ex}}$ with $\mathrm{S} / \mathrm{B}$. $\eta_{\text {ex }}$ decline slightly over the $\mathrm{S} / \mathrm{B}$ range of $0.4-1.0$. These implies that the $\mathrm{S} / \mathrm{B}$ is a minor variable for this process. Briefly, smaller S/B is favorable on the condition that the requirements of gasification are satisfied. This result can guide the selection of gasifier.

3.4. Effects of $\eta_{\mathrm{WE}}$. Apparently, $\eta_{\mathrm{WE}}$ only has influences on the process efficiencies. Figure 7 shows that when HHV-based

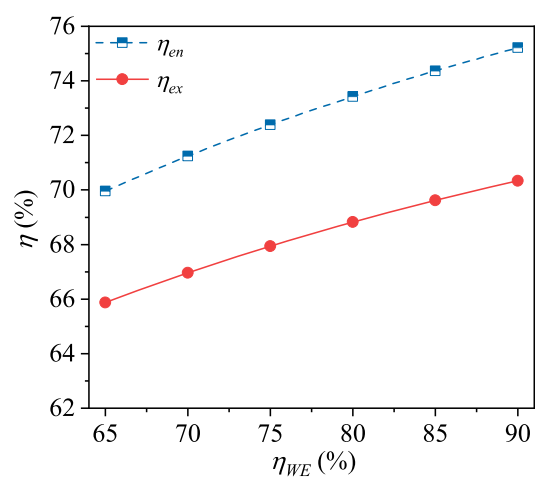

Figure 7. Variations of $\eta_{\mathrm{en}}$ and $\eta_{\mathrm{ex}}$ with $\eta_{\mathrm{WE}}$.

$\eta_{\mathrm{WE}}$ increases from 65 to $90 \%, \eta_{\mathrm{en}}$ and $\eta_{\mathrm{ex}}$ gradually improve from 69.9 to $75.2 \%$ and from 65.9 to $70.3 \%$, respectively. As indicated by the cases in Figure 4, the electricity for water electrolysis accounts for more than $90 \%$ of the total electricity consumption of the process. Therefore, the efficiency of water electrolysis has direct and significant influence on the overall process efficiencies. One should pay attention to this variable and the improvement in $\eta_{\mathrm{WE}}$ is highly expected.

3.5. Effects of $W R$ and $p_{M}$. The amounts of water for electrolysis and $\mathrm{H}_{2}$ added into the FBMR increase proportionally with the increase in the amount of WR. Figure 8

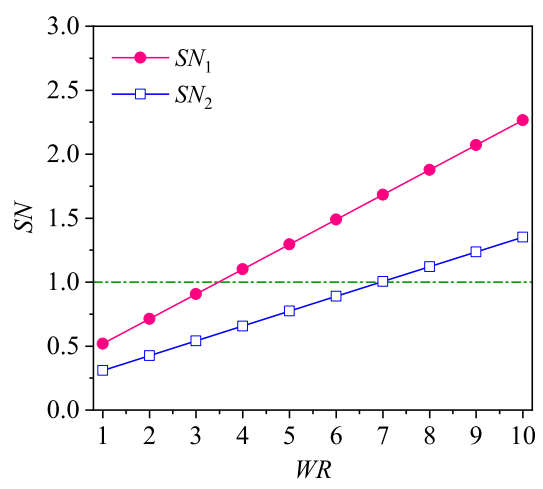

Figure 8. Variations of $\mathrm{SN}_{1}$ and $\mathrm{SN}_{2}$ with $\mathrm{WR}$.

indicates that at a WR of about $3.5, \mathrm{SN}_{1}$ is equal to 1 . When WR is less than 3.5 , that is, $\mathrm{SN}_{1}<1$, the amount of $\mathrm{H}_{2}$ is not enough to covert $\mathrm{CO}$ in product gas. Then, WGSR plays an important role in the methanation synthesis. It coverts $\mathrm{CO}$ into $\mathrm{CO}_{2}$ and generates $\mathrm{H}_{2}$ from $\mathrm{H}_{2} \mathrm{O}$ for $\mathrm{CO}$ methantion RR1. While $\mathrm{SN}_{2}$ reaches 1 at a WR of about 7, which means that $\mathrm{CO}$ and $\mathrm{CO}_{2}$ can be sufficiently converted to $\mathrm{CH}_{4}$ to obtain syngas with a high concentration of $\mathrm{CH}_{4}$. In detail, the effects of WR on syngas composition are as shown in Figure 9a-c.

Figure 9a shows that $\mathrm{CH}_{4}$ concentration first increases, then declines with the increase in $\mathrm{WR}$, and reaches the maximum values around a $\mathrm{WR}$ of 7 (i.e., $\mathrm{SN}_{2} \approx 1$ ). At the ascent stage, with the increase in $\mathrm{H}_{2}$ added into the FBMR, the methanation 

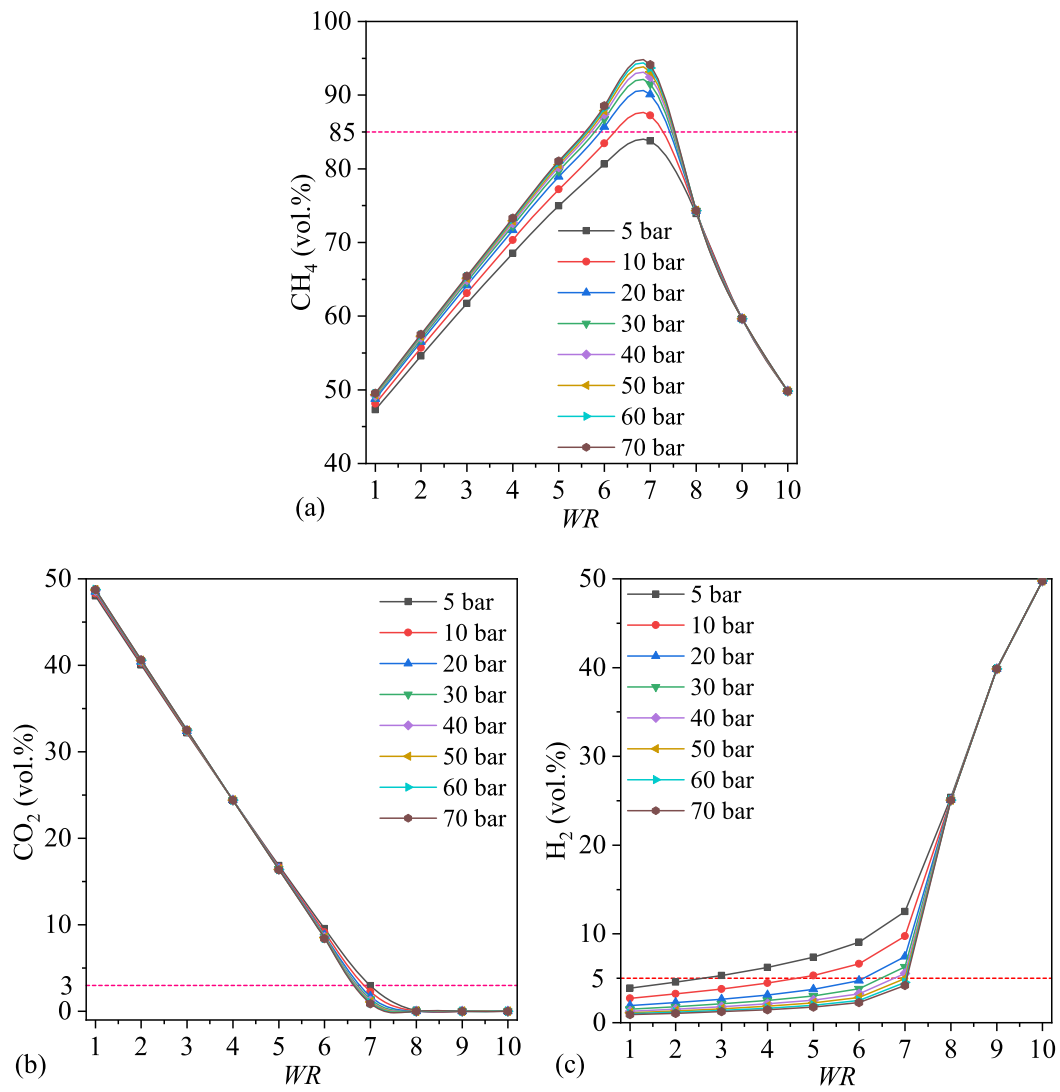

Figure 9. Variations of syngas composition with WR: (a) $\mathrm{CH}_{4}$, (b) $\mathrm{CO}_{2}$, and (c) $\mathrm{H}_{2}$.
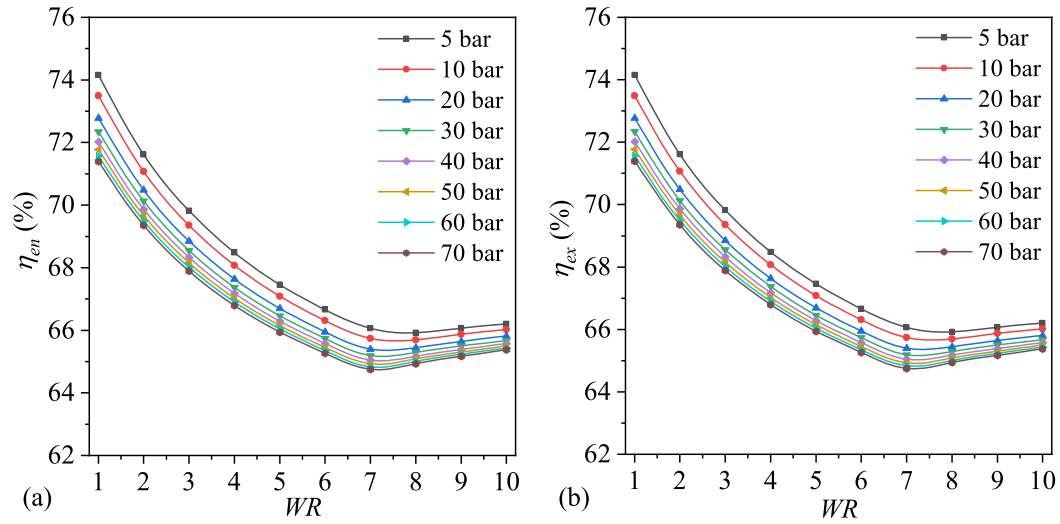

Figure 10. Variations of $\eta_{\text {en }}$ and $\eta_{\text {ex }}$ with WR: (a) $\eta_{\text {en }}$ and (b) $\eta_{\text {ex }}$.

reactions $\mathrm{RR} 1$ and $\mathrm{RR} 2$ shift toward the right, that is, $\mathrm{CH}_{4}$ side. As a result, $\mathrm{CH}_{4}$ concentration continuously increases, while $\mathrm{CO}_{2}$ concentration steadily declines (seeing Figure 9b). At this stage, most $\mathrm{H}_{2}$ is converted into $\mathrm{CH}_{4}$ and its concentration maintains at low levels $(<10 \%$, seeing Figure 9c). When WR exceeds the critical value of 7 (i.e., $\mathrm{SN}_{2}>1$ ), $\mathrm{CO}$ and $\mathrm{CO}_{2}$ have been depleted, then $\mathrm{CO}_{2}$ concentration remains in extremely low levels (seeing Figure 9b), and little $\mathrm{CH}_{4}$ could be further generated. At this stage, the addition of $\mathrm{H}_{2}$ only dilutes $\mathrm{CH}_{4}$ concentration. Hence, as shown in Figure 9a,c, $\mathrm{CH}_{4}$ concentration reduces obviously while $\mathrm{H}_{2}$ concentration improves sharply, respectively.

Figure 9 also shows the variations of syngas composition with $p_{\mathrm{M}}$. The $\mathrm{CH}_{4}$ concentration in natural gas commonly exceeds 85 vol \%. According to the Chinese technical standard "coal-based SNG", $\mathrm{H}_{2}$ and $\mathrm{CO}_{2}$ concentrations should not exceed 5 and $3 \mathrm{~mol} \%$, respectively. The effects of $\mathrm{WR}$ and $p_{\mathrm{M}}$ clearly indicates that only a combination of WR and $p_{M}$ with their narrow ranges can directly result in SNG composition without post $\mathrm{CO}_{2}$ separation. In this study, the conditions for SNG production are as follows: WR is around 7 and $p_{M}$ is not less than 50 bar. Figure 9 also indicates that by varying WR, this process can generate all the types of syngas with a quality between TSB and SNG. Thus, the process has a powerful flexibility in the final product, and TSB and SNG are only two typical products.

Figure $10 \mathrm{a}, \mathrm{b}$ shows the variations of $\eta_{\mathrm{en}}$ and $\eta_{\mathrm{ex}}$ with WR, respectively. With the increase in WR, both $\eta_{\mathrm{en}}$ and $\eta_{\mathrm{ex}}$ first decrease and then increase at a given $p_{\mathrm{M}}$. They reach minimum values around a WR of $7\left(\mathrm{SN}_{2} \approx 1\right)$. These variations are just contrary to those of $\mathrm{CH}_{4}$ concentration (Figure 9a); however, the reasons are the same. The "decrease" is caused by the 
characteristic of exothermic reactions RR1 and RR2, which inevitably result in energy or exergy losses. By comparison, the "increase" is caused by the added $\mathrm{H}_{2}$ that cannot further react due to the absence of reactants $\mathrm{CO}$ and $\mathrm{CO}_{2}$. Both the maximum values of $\eta_{\text {en }}$ and $\eta_{\text {ex }}$ are at a WR of 1 , which means that the electrolysis rate is just sufficient to satisfy the $\mathrm{O}_{2}$ demand of the gasifier. The condition for maximum $\eta_{\mathrm{en}}$ and $\eta_{\mathrm{ex}}$ is the same as that of the SNG process integrating WE and $\mathrm{CO}_{2}$ separation. ${ }^{16}$ However, the products are quite different. Additionally, $\eta_{\mathrm{en}}$ and $\eta_{\mathrm{ex}}$ gradually decrease with the increase in $p_{\mathrm{M}}$, as the increase in $p_{\mathrm{M}}$ favors the exothermic methanation synthesis.

In short, lower WR and $p_{M}$ are beneficial to the energy and exergy efficiencies; however, they lead to the syngas that is equivalent or similar to TSB. Thus, there is a contradiction between composition and efficiencies. Most rural areas in China lack natural gas facilities. With the matched newly construction of facilities, both TSB and SNG would be feasible to produce, pipe, and use. Then, the following cost assessment includes both types of products.

3.6. Performance of Typical Products and Electricity Storage. Guided by the abovementioned results, Table 5

Table 5. Technical Performances of TSB and SNG Produced by Single-Stage and Two-Stage Gasifiers

\begin{tabular}{|c|c|c|c|c|}
\hline gas type & TSB & TSB & SNG & SNG \\
\hline gasifier & single-stage & two-stage & single-stage & two-stage \\
\hline SR & 0.159 & 0.107 & 0.159 & 0.107 \\
\hline WR & 1 & 1 & 4.92 & 6.81 \\
\hline$p_{\mathrm{M}}$ & 5 & 5 & 70 & 70 \\
\hline \multicolumn{5}{|c|}{ Syngas Composition (vol \%, db) } \\
\hline $\mathrm{CH}_{4}$ & 47.47 & 47.62 & 93.67 & 93.72 \\
\hline $\mathrm{H}_{2}$ & 3.61 & 3.41 & 3.51 & 3.35 \\
\hline $\mathrm{CO}$ & 0.03 & 0.03 & 0.001 & 0.001 \\
\hline $\mathrm{CO}_{2}$ & 48.09 & 48.14 & 2.03 & 2.14 \\
\hline $\mathrm{N}_{2}$ & 0.60 & 0.60 & 0.60 & 0.60 \\
\hline $\mathrm{HHV}\left(\mathrm{MJ} / \mathrm{Nm}^{3}\right)$ & 19.33 & 19.36 & 37.67 & 37.67 \\
\hline $\mathrm{LHV}\left(\mathrm{MJ} / \mathrm{Nm}^{3}\right)$ & 17.39 & 17.43 & 33.92 & 33.92 \\
\hline $\operatorname{SCE}\left(\mathrm{MJ} / \mathrm{Nm}^{3}\right)$ & 18.00 & 18.03 & 35.13 & 35.13 \\
\hline$Y\left(\mathrm{Nm}^{3} / \mathrm{kg}\right)$ & 0.839 & 0.838 & 0.839 & 0.837 \\
\hline$\eta_{\mathrm{en}}(\%)$ & 68.4 & 74.1 & 62.5 & 64.8 \\
\hline$\eta_{\mathrm{ex}}(\%)$ & 64.6 & 69.5 & 62.0 & 64.1 \\
\hline$E n_{\text {bio }}\left(\mathrm{MW}_{\mathrm{LHV}}\right)$ & 109.0 & 109.0 & 109.0 & 109.0 \\
\hline $\mathrm{Ex}_{\mathrm{bio}}\left(\mathrm{MW}_{\mathrm{SCE}}\right)$ & 123.3 & 123.3 & 123.3 & 123.3 \\
\hline$P_{\mathrm{RE}}\left(\mathrm{MW}_{\mathrm{el}}\right)$ & 39.1 & 27.7 & 206.8 & 197.2 \\
\hline GSC (kWh/kg) & 1.57 & 1.11 & 8.27 & 7.89 \\
\hline NSC (kWh/kg) & 0.98 & 0.75 & 8.52 & 8.32 \\
\hline $\mathrm{EC}_{\mathrm{T}}$ (million CNY) & 71.82 & 70.85 & 138.42 & 140.19 \\
\hline $\mathrm{EC}_{\mathrm{WE}}($ million $\mathrm{CNY})$ & 25.77 & 19.75 & 74.96 & 71.44 \\
\hline $\mathrm{H}_{2}\left(\mathrm{Nm}^{3} / \mathrm{h}\right)$ & 9856 & 6628 & 48522 & 45163 \\
\hline $\mathrm{UPC}\left(\mathrm{CNY} / \mathrm{Nm}^{3}\right)$ & 1.267 & 1.130 & 3.879 & 3.746 \\
\hline
\end{tabular}

summarizes the technical performances of four cases with the combinations of gas types (TSB and SNG) and gasifier types (single-stage and two-stage). The operating parameters for TSB production are less or lower than those for SNG. WR changes according to gasifier type and gas type. As discussed above, in the case of TSB, $\eta_{\mathrm{en}}$ and $\eta_{\mathrm{ex}}$ with a two-stage gasifier are obviously higher than those with a single-stage gasifier, respectively. However, in the case of SNG, the differences in the efficiencies with two types of gasifiers are much smaller. The reason is that in the case of SNG, $P_{\mathrm{RE}}$ is about 1.6-and
1.8 times of those of the energy input of biomass $\left(\mathrm{En}_{\mathrm{bio}}\right.$ or $\mathrm{Ex}_{\mathrm{bio}}$, Table 5). The efficiencies are dominated by $P_{\mathrm{RE}}$ as one term in the denominator of eqs 5 and 6 . The recovered heat $Q_{1}$, about $9 \%$ of the energy input of biomass, apparently has little contributions to both energy and exergy efficiencies.

Table 5 also shows that the TSB process has higher energy and exergy efficiencies compared with the SNG process. From this perspective, TSB is the better option than SNG. Additionally, the energy and exergy efficiencies of the conventional SNG process with sufficient optimization can reach up to $73.9^{5}$ and $71.8 \%,{ }^{46}$ respectively, which are approximately 10 and 8 percentage points higher than those of this process for SNG production (64.8 and 64.1\%). However, TSB is generated as the final product; this process has comparative energy and exergy efficiencies (74.1 and $69.5 \%$ ). The comparison of TSB and SNG with conventional SNG demonstrates the advantages of TSB in the aspect of efficiencies. Additionally, the yields of TSB and SNG are around $0.838 \mathrm{Nm}^{3} / \mathrm{kg}$, which are quite greater than that of conventional SNG from wheat straw $\left(0.282-0.334 \mathrm{Nm}^{3}\right.$ / $\left.\mathrm{kg}^{23,26}\right)$. The difference can be regarded as the indirect manifestation of stored electricity.

One of the purposes of a PtG process is to store the renewable electricity. Thus, the performance of electricity storage should be concerned. Inspired by the specific energy density of battery (in $\mathrm{Wh} / \mathrm{kg}$ ), we propose the concept of specific capacity of electricity storage for such processes. Because feedstock and product differ greatly from each other in physical and chemical properties, two indicators are defined to evaluate the performances of electricity storage of both biomass and syngas. First, the gross-specific capacity of electricity storage (GSC, in $\mathrm{kWh} / \mathrm{kg}$ ) is defined as the amount of the renewable electricity inputted and converted by a specific biomass and renewable power-to-syngas process relative to $1 \mathrm{~kg}$ of the biomass feedstock, and it can be calculated as follows

$$
\mathrm{GSC}=\frac{P_{\mathrm{RE}}}{m_{\text {bio }}}
$$

where $m_{\text {bio }}$ is the mass flow rate of biomass, in $\mathrm{kg} / \mathrm{h}$. It can be applied to determine how much biomass is required or should be reserved for a renewable electricity-storage plant. In turn, it can be used to determine how much renewable electricity can be stored based on the local biomass resource.

Second, the net specific capacity of electricity storage (NSC, in $\mathrm{kWh} / \mathrm{kg}$ ) is defined as the amount of the equivalent renewable electricity embedded in $1 \mathrm{~kg}$ of the biofuel, and it can be calculated as follows

$$
\mathrm{NSC}=\frac{\mathrm{Ex}_{\mathrm{SG}} \cdot\left(\frac{3.6 P_{\mathrm{RE}}}{\mathrm{Ex}_{\mathrm{bio}}+3.6 P_{\mathrm{RE}}}\right)}{3.6 \cdot m_{\mathrm{SG}}}=\frac{3.6 P_{\mathrm{RE}}}{\mathrm{Ex}_{\mathrm{bio}}+3.6 P_{\mathrm{RE}}} \cdot \frac{\mathrm{SCE}_{\mathrm{SG}}}{3.6}
$$

where $m_{\mathrm{SG}}$ is the mass flow rate of the product, in $\mathrm{kg} / \mathrm{h} . \mathrm{Ex}_{\mathrm{SG}}$ is the chemical exergy flow rate of syngas, in $\mathrm{MJ} / \mathrm{h}$. Here, $\mathrm{SCE}_{\mathrm{SG}}$ is SCE of the syngas, in $\mathrm{MJ} / \mathrm{kg}$. The numerator of eq 10 denotes the renewable electrical power that is veritably and availably embedded in the biofuel. As the energy content of biofuel is converted from that of biomass and renewable electricity, we assume that the proportion of the embedded renewable electricity in the energy content of biofuel is the same as that of renewable electrical power $\left(3.6 P_{\mathrm{RE}}\right)$ in the total 
energy input $\left(\mathrm{Ex}_{\mathrm{bio}}+3.6 P_{\mathrm{RE}}\right)$ for the whole conversion process. Among the three thermodynamic parameters of biomass, that is, LHV, HHV and SCE, we suggest using chemical exergy to quantize the energy content. The reason is that chemical exergy represents the maximum work that can be obtained, of which the energy quality is equivalent to that of electricity. This indicator can be used to evaluate or compare the electricity-storage abilities of different biofuels or process configurations.

Obviously, GSC and NSC are closely relevant to the thermochemical properties of the product (i.e., the energy carrier). Table 5 shows that GSC $(7.89 \mathrm{kWh} / \mathrm{kg})$ and NSC $(8.32 \mathrm{kWh} / \mathrm{kg})$ via SNG are 5-7 times of those via TSB (1.11 and $0.75 \mathrm{kWh} / \mathrm{kg}$, respectively). From this point of view, SNG is a preferred energy carrier due to its larger GSC and NSC. Additionally, GSC and NSC are also related to the process configuration and its efficiency. For example, when the final storage carrier is fixed, either TSB or SNG, one should choose the process configuration with lower GSC and NSC because that process has a higher efficiency and a less energy or exergy loss. However, this result may result in confusion. Here, we recommend using GSC and NSC only to quantify and compare the storage abilities of different types of feedstock or biofuels rather than to measure the process efficiencies. The conversion performances could be thoroughly evaluated by the energy and exergy efficiencies.

Table 5 shows that the NSC via TSB $(0.75 \mathrm{kWh} / \mathrm{kg})$ is less than the GSC (1.11 kWh/kg); however, the NSC via SNG $(8.32 \mathrm{kWh} / \mathrm{kg})$ is greater than the GSC $(7.89 \mathrm{kWh} / \mathrm{kg})$. This is caused by the big difference in the amount of electricity consumed by the WE system. The specific energy density of the lithium-ion battery pack in Telsa electrical vehicles reaches up to $0.160 \mathrm{kWh} / \mathrm{kg}$ in $2019 .^{47}$ The GSC and NSC via TSB are 6.9 and 4.7 times of the specific energy density of the lithium-ion battery pack, respectively, while those via SNG are up to 49.5 and 52.0 times, respectively. Thus, TSB and SNG are excellent energy carriers for large-scale and long-term electricity storage compared with lithium-ion batteries. With GSC and NSC, we can separately or synthetically evaluate and compare various biofuels and process configurations that play a role in renewable electricity storage in future studies.

\section{ECONOMIC ASSESSMENT}

4.1. Costs of TSB and SNG. The equipment costs of the main devices are calculated using the simulated technical data and the equipment values are listed in Table 6. Take the

Table 6. Summary of PC and EC for SNG Production with Single-Stage and Two-Stage Gasifiers

\begin{tabular}{|c|c|c|c|c|c|}
\hline \multirow[b]{2}{*}{ system } & \multirow[b]{2}{*}{ benchmark } & \multicolumn{2}{|c|}{ PC } & \multicolumn{2}{|c|}{$\begin{array}{c}\mathrm{EC}_{2019} \text { (million } \\
\mathrm{CNY} \text { ) }\end{array}$} \\
\hline & & $\begin{array}{l}\text { single- } \\
\text { stage }\end{array}$ & $\begin{array}{l}\text { two- } \\
\text { stage }\end{array}$ & $\begin{array}{l}\text { single- } \\
\text { stage }\end{array}$ & $\begin{array}{l}\text { two- } \\
\text { stage }\end{array}$ \\
\hline $\mathrm{EC}_{\mathrm{G}}$ & biomass $(\mathrm{t} / \mathrm{h})$ & 25 & 25 & 15.02 & 22.53 \\
\hline $\mathrm{EC}_{\mathrm{PGCC}}$ & $P G(t / h)$ & 29.7 & 28.9 & 13.60 & 13.31 \\
\hline $\mathrm{EC}_{\mathrm{CM}}$ & $P G(t / h)$ & 29.7 & 28.9 & 7.42 & 7.29 \\
\hline $\mathrm{EC}_{\mathrm{M}}$ & syngas $(\mathrm{t} / \mathrm{h})$ & 34.1 & 33.0 & 14.41 & 14.09 \\
\hline $\mathrm{EC}_{\mathrm{HTs}}$ & water $(\mathrm{t} / \mathrm{h})$ & 150.3 & 155.2 & 0.84 & 0.86 \\
\hline $\begin{array}{l}\mathrm{EC}_{\mathrm{WE}} \\
\quad(\mathrm{SNG})\end{array}$ & $\mathrm{H}_{2}\left(\mathrm{Nm}^{3} / \mathrm{h}\right)$ & 48522 & 45163 & 74.96 & 71.44 \\
\hline $\begin{array}{l}\mathrm{EC}_{\mathrm{ORC}} \\
(\mathrm{SNG})\end{array}$ & $\begin{array}{l}\text { power output } \\
\text { (MW) }\end{array}$ & 15.2 & 12.5 & 12.15 & 10.66 \\
\hline
\end{tabular}

process with a two-stage gasifier as an example, the scale of WE for SNG production is about 6.8 times of that for TSB. When $\mathrm{SNG}$ is chosen as the product, $\mathrm{EC}$ of WE is the most expensive equipment. The industry of WE for renewable electricity storage is in the early stage in China and its equipment cost will reduce dramatically in future with the expansion in the industrial scale.

The equipment cost of the four cases is summarized in Table 5. Compared with the process with a two-stage gasifier, the EC of the gasifier of the process with a single-stage gasifier decreases dramatically, while the EC of WE increases obviously and the ECs of other systems increase. As a result, the total equipment cost $\left(\mathrm{EC}_{\mathrm{T}}\right)$ with a single-stage gasifier is slightly greater than that with a two-stage gasifier for the same product, although the single-stage gasifier is much cheaper. The reason is that the single-stage gasifier with higher SR needs a larger scale of electrolysis device. For example, in the case of SNG, the $\mathrm{EC}_{\mathrm{WE}}$ with single-stage and two gasifiers is 74.96 and 71.44, respectively, in million CNY. The flow rates of PG and syngas with a single-stage gasifier also increase because more oxygen is added into the gasifier, which leads to small increases in equipment cost of the related auxiliary devices (Table 6). The abovementioned results indicate that from the perspective of the total equipment cost, the process also should integrate the two-stage gasifier. The comparison between $\mathrm{EC}_{\mathrm{WE}}$ of TSB and SNG shows that the $\mathrm{EC}_{\mathrm{WE}}$ of $\mathrm{SNG}$ is so large that it is similar to the $\mathrm{EC}_{\mathrm{T}}$ of TSB. As other devices are relatively mature in technology and cost and the industry of WE for renewable electricity storage in China is very weak now, reducing $\mathrm{EC}_{\mathrm{WE}}$ is the potentially promising way to reduce the total equipment cost.

The typical selling price of natural gas in Eastern China is about $2.40 \mathrm{CNY} / \mathrm{Nm}^{3}$. It can be regarded as the SNG's critical cost. If the UPC of SNG is lower than the critical cost, the project is profitable. A survey released in 2018 shows that the prices of biogas in different provinces in China range from 1.01 to 1.48 with an average value of 1.26 , in $\mathrm{CNY} / \mathrm{m}^{3}{ }^{48} \mathrm{We}$ assume that the critical cost of TSB is $1.26 \mathrm{CNY} / \mathrm{Nm}^{3}$ in the following discussion. Table 5 shows that the UPCs of SNG (3.746 CNY $/ \mathrm{Nm}^{3}$ ) are dramatically higher than its critical cost $\left(2.40 \mathrm{CNY} / \mathrm{Nm}^{3}\right)$. It implies that the production of $\mathrm{SNG}$ is unprofitable at the base scenario. By comparison, the UPCs of TSB $\left(1.130 \mathrm{CNY} / \mathrm{Nm}^{3}\right)$ are lower than its critical cost $(1.26$ $\left.\mathrm{CNY} / \mathrm{Nm}^{3}\right)$, which can make a profit.

The composition of the UPCs are further analyzed to determine the biggest component and improve the cost competitiveness. Figure $11 \mathrm{a}$ indicates that $\mathrm{C}_{\mathrm{EL}}$ is the biggest component in SNG's UPC (74.1\%), and the following component is $C_{\text {bio }}(9.4 \%)$. Figure $11 \mathrm{~b}$ indicates that the distribution of TSB's UPC is more even. However, the same result is that $C_{\mathrm{EL}}$ and $C_{\text {bio }}$ are the top two components in TSB's UPC (35.1 and $31.7 \%$, respectively). Thus, the influences of electricity cost and biomass cost are focused on in the following sensitivity analysis. Additionally, the result also shows that the revenue by selling oxygen at a price of $0.2 \mathrm{CNY} / \mathrm{m}^{3}$ has a small impact on the TPC and UPC.

4.2. Sensitivity Analysis. In order to assess the effect of the most influential variables on UPC, a sensitivity analysis is carried out by changing the variables while the others are held at their base values. Based on the abovementioned results, the sensitivity analysis focuses on the following important variables, plant scale $(S), \mathrm{EC}_{\mathrm{WE}}, C_{\mathrm{EL}}$, and $C_{\mathrm{bio}}$. The fluctuation of the variables is specified with the reference data from the 

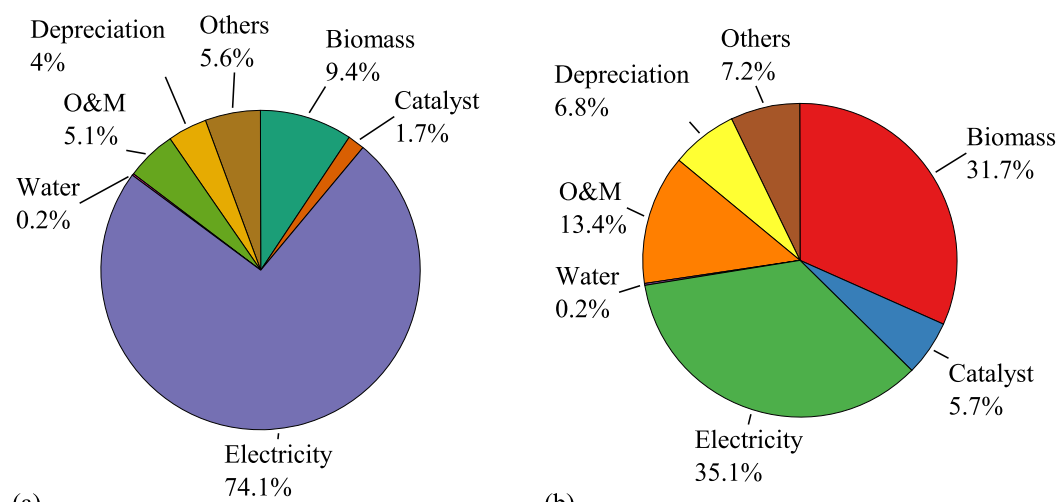

(a)

(b)

Figure 11. Composition of UPC: (a) SNG and (b) TSB.
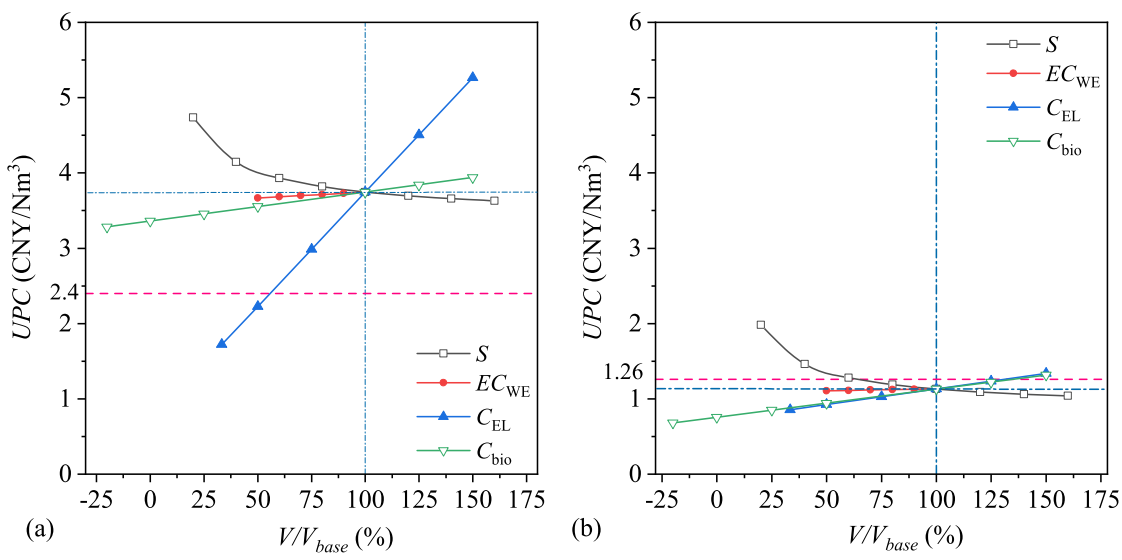

Figure 12. Sensitivity analysis of UPC: (a) SNG and (b) TSB.
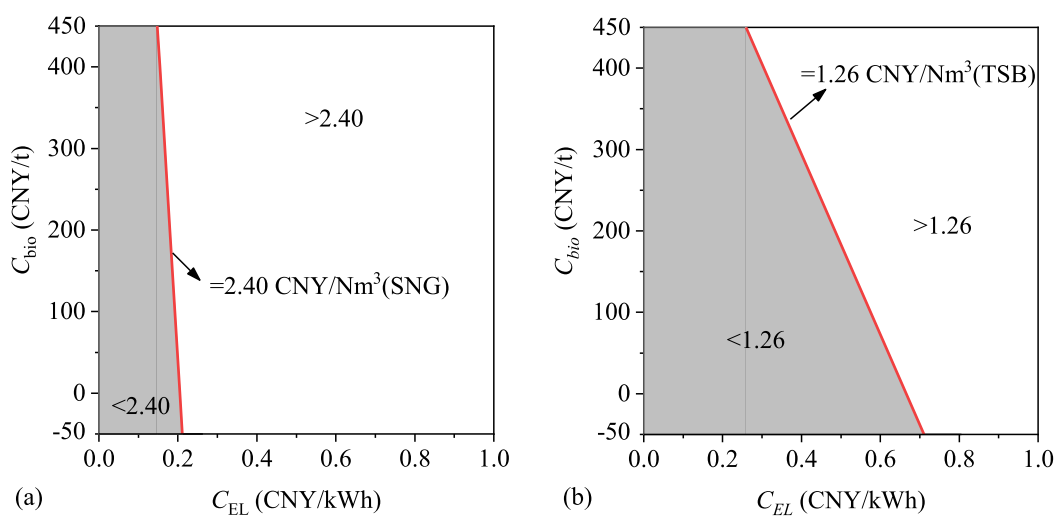

Figure 13. Effects of $C_{\mathrm{EL}}$ and $C_{\text {bio }}$ on UPC: (a) SNG and (b) TSB.

similar or related cases. ${ }^{23,49}$ It is assumed that in near future, with the rapid development of WE, approximately $50 \%$ reduction in the manufacturing sector is achievable. ${ }^{13}$ The ranges of these variables are as given below: $S=5-40 \mathrm{t} / \mathrm{h}$ $(20-160 \%) ; \mathrm{EC}_{\mathrm{WE}}=50-100 \% ; C_{\mathrm{EL}}=0.1-0.45 \mathrm{CNY} / \mathrm{kWh}$ $(33.33-150 \%)$; and $C_{b i o}=-60-450 \mathrm{CNY} / \mathrm{t}(-20$ to $150 \%)$. The variations of UPC with these variables are as shown in Figure 12.

Figure 12a presents the sensitivity results about SNG's UPC. When the plant scale increases from $20 \%(5 \mathrm{t} / \mathrm{h})$ to $160 \%(40$ $\mathrm{t} / \mathrm{h}$ ), the UPC decreases rapidly at first and then slowly. The reasonable plant scale should not be less than $60 \%$ of the base value $(15 \mathrm{t} / \mathrm{h})$. Figure $12 \mathrm{a}$ also shows that the UPC has little sensitivity toward $\mathrm{EC}_{\mathrm{EL}}$ judging from the slopes of the curves.
The UPC proportionally increases with the increase in either $C_{\mathrm{EL}}$ or $C_{\mathrm{bio}} . C_{\mathrm{EL}}$ is the most influential variable for SNG's UPC. Nevertheless, it should be noticed that $C_{\text {bio }}$ can be negative values, and the cost competitiveness will dramatically rise under that condition. The UPC of SNG at the base scenario is much higher than its critical cost $\left(2.40 \mathrm{CNY} / \mathrm{Nm}^{3}\right)$ as indicated by the red dashed line in Figure 12a. The SNG project would be profitable when $C_{\mathrm{EL}}$ is less than $50 \%$ of its base value (about $0.15 \mathrm{CNY} / \mathrm{kWh}$ ). In 2019, the basic price of residential electricity is about $0.6 \mathrm{CNY} / \mathrm{kWh}$, while industrial electricity price is greater than $0.8 \mathrm{CNY} / \mathrm{kWh}$. There is a big economic challenge to operate the $\mathrm{SNG}$ project at a $C_{\mathrm{EL}}$ of $0.15 \mathrm{CNY} / \mathrm{kWh}$. 
Figure $12 \mathrm{~b}$ shows that the sensitivity results of TSB are similar to those of SNG. Compared with the results of SNG, the UPC of TSB is much less sensitive to $C_{\mathrm{EL}}$, while it shows slightly little sensitivity toward the remaining variables. As indicated by the red dashed lines in Figure $12 \mathrm{~b}$, the UPC of TSB at the base scenario is visibly lower than its critical cost $\left(1.26 \mathrm{CNY} / \mathrm{Nm}^{3}\right)$. TSB as the product is more likely to be profitable when variables fluctuate in the ranges. Unless the plant scale is too small (approximately $<50 \%$ of base value, i.e., $12.5 \mathrm{t} / \mathrm{h}$ ), the UPC of TSB would not exceed its critical cost by varying a variable within the specified range.

Figure 13 focuses on the effects of combined $C_{\mathrm{EL}}$ and $C_{\mathrm{bio}}$ on UPC, while other variables are fixed at their base values. The $\mathrm{UPC}$ on the red line is constantly $2.40 \mathrm{CNY} / \mathrm{Nm}^{3}$ for $\mathrm{SNG}$ (Figure 13a) or $1.33 \mathrm{CNY} / \mathrm{Nm}^{3}$ for TSB (Figure $13 \mathrm{~b}$ ). The combinations of $C_{\mathrm{EL}}$ and $C_{\mathrm{bio}}$ corresponding to the points in the gray areas can make a profit. The comparison between Figure 13a,b clearly indicates that TSB has much wider ranges of $C_{\mathrm{EL}}$ and $C_{\text {bio }}$ as well as their combination to gain profit. To sum up, the UPC analysis confirms the advantages of TSB over SNG in the aspect of cost.

\section{CONCLUSIONS}

In this work, a biomass and renewable power-to-syngas process for high-quality syngas production integrating oxygen gasification, water electricity, and methanation without $\mathrm{CO}_{2}$ separation is simulated and investigated from technical and economic aspects. For the first time, the work investigated the process configuration integrating a two-stage gasifier, considered TSB as a new type of product, proposed gross and net specific capacity of electricity storage, and evaluated the unit production costs under the Chinese scenario. The main findings of the current study are presented below:

Compared with the single-stage gasifier, the two-stage gasifier utilizes the high-temperature part of heat in PG more sufficiently and operates with a smaller SR, which results in a smaller scale of the matched WE system. The process configuration with a two-stage gasifier has advantages of about 5 percentage points in energy and exergy efficiencies over that with a single-stage gasifier. It also owns lower total equipment cost and unit production cost mainly contributed by the WE system. Reducing equipment cost of electrolyzer is the potentially promising way to reduce the total equipment cost.

WR is an important parameter significantly affecting both technical and economic indicators of this process. The process generates TSB at a WR of 1 or SNG at a WR around 7. Only with the proper combinations of WR $(\sim 7)$ and $p_{M}$ (>50 bar), the process can directly generate SNG that meets the Chinese technical standard, which is a valuable reference for other countries with different limiting values. The adaptive $p_{M}$ of the FBMR in this process could be several times higher than that in the conventional SNG production process with $\mathrm{CO}_{2}$ separation. $^{50}$

The process can generate two typical products: TSB and SNG. At the base scenario, TSB has very high energy and exergy efficiencies $(\leq 74.1 \%)$ and profitable UPC (1.130 CNY/ $\mathrm{Nm}^{3}$ ), while SNG has relatively low efficiency $(\leq 64.8 \%)$ and unprofitable UPC (3.746 CNY/ $\left.\mathrm{Nm}^{3}\right)$. TSB is profitable over wider ranges of the sensitivity variables, while SNG can only gain profit with very low biomass cost and/or electricity cost.

Two indicators GSC and NSC are proposed by this work to evaluate the electricity-storage capacities of biomass and biofuels, respectively. SNG only has significant advantages over TSB in capacities of electricity storage. The GSC and NSC via TSB are 6.9 and 4.7 times of the specific energy density of the lithium-ion battery pack, respectively, while those via SNG are up to 49.5 and 52.0 times, respectively. From this perspective, both TSB and SNG are excellent energy carriers for large-scale electricity storage compared with lithium-ion batteries. In future, we can employ the proposed indicators to compare the competitiveness of a biofuel project with that of a battery project for electricity storage.

As both biomass and renewable power are sustainable and relatively clean, this process with a two-stage gasifier is a promising and efficient pathway to generate sustainable gaseous fuels, store renewable power massively, and utilize biomass and wastes. The quantitative assessments on sustainability and environmental impacts deserve further investigation including the comparison between TSB and SNG. Although some pilot-scale two-stage gasifiers had been studied, ${ }^{18,51}$ there is still much work that needs to be done for scale up and commercialization. Additionally, other technologies driven by renewable power and having connection with oxygen and/or steam gasification are also worth investigating in future, such as low-power oxygen production techniques. Similarly, two-stage gasifier and alternative technologies driven by renewable power may benefit other power-to-X processes using biomass as a carbon source, for example, bio-methanol, bio-dimethyl ether, and so forth, which are recommended for further efforts.

\section{ASSOCIATED CONTENT}

\section{SI Supporting Information}

The Supporting Information is available free of charge at https://pubs.acs.org/doi/10.1021/acsomega.1c03489.

Verification of the oxygen-steam gasification; verification of the methanation synthesis; model blocks and operation parameters of the auxiliary devices; total capital investment model and percentage for each component; values of $\mathrm{PC}_{\mathrm{ref}}, \mathrm{EC}_{\mathrm{ref}}, \mathrm{CEPCI}_{\mathrm{ref}}$ and $n$ for estimating equipment costs; and parameters and assumptions of the unit product cost model (PDF)

\section{AUTHOR INFORMATION}

\section{Corresponding Author}

Guohui Song - School of Energy and Power Engineering, Nanjing Institute of Technology, Nanjing, Jiangsu 211167, China; (1) orcid.org/0000-0002-2749-427X; Email: ghsong@njit.edu.cn,sghcs2003@163.com

\section{Authors}

Liang Wang - School of Energy and Power Engineering, Nanjing Institute of Technology, Nanjing, Jiangsu 211167, China

Ailin Yao - School of Energy and Power Engineering, Nanjing Institute of Technology, Nanjing, Jiangsu 211167, China

Xiaobo Cui - School of Energy and Power Engineering, Nanjing Institute of Technology, Nanjing, Jiangsu 211167, China

Jun Xiao - Key Laboratory of Energy Thermal Conversion and Control of Ministry of Education, School of Energy and Environment, Southeast University, Nanjing, Jiangsu 210096, China; orcid.org/0000-0003-0002-2878

Complete contact information is available at: 
https://pubs.acs.org/10.1021/acsomega.1c03489

\section{Author Contributions}

The manuscript was written through contributions of all authors. All authors have given approval to the final version of the manuscript.

\section{Notes}

The authors declare no competing financial interest.

\section{ACKNOWLEDGMENTS}

This work was financially supported by the Scientific Foundation of Nanjing Institute of Technology (YKJ201818 and QKJ201703), the National Natural Science Foundation of China (grant no. 51806095), and the Natural Science Foundation of Jiangsu Province of China (grant no. BK20181022).

\section{ABBREVIATIONS}

CL cooler

CM compressor

FBMR fluidized bed methanation reactor

G gasification

HT heater

M methanation synthesis

ORC organic Rankine cycle

PG producer gas

PGCC producer gas cleaning and cooling

PM pump

$\mathrm{RE}$ renewable electricity

SG syngas

SNG synthetic natural gas

TSB thermochemical synthetic biogas

WE water electrolysis

WG water for gasification

WM water for methanation

ad air-dried

$\mathrm{db} \quad$ dry basis

w water

\section{SUBSCRIPTS}

ES electricity storage

en energy

ex exergy

ref reference value or case

$\mathrm{T}$ tota

bio biomass

\section{VARIABLES}

C cost

EC equipment cost

En energy flow rate

Ex exergy flow rate

FCI fixed capital investment

GSC gross specific capacity of electricity storage of feedstock via a product

HHV higher heating value

LHV lower heating value

NSC net specific capacity of electricity storage via a product $P \quad$ electrical power

PC production capacity

$Q$ heat flow rate

$\mathrm{S} / \mathrm{B}$ steam/biomass mass ratio
SCE specific chemical exergy

$\mathrm{SN}$ stoichiometric number

SR stoichiometric ratio of $\mathrm{O}_{2}$

$T$ temperature

TCI total capital investment

TPC total production cost

UPC unit product cost

$V \quad$ value of a variable

WC working capital

WR water ratio for electrolysis

$m$ mass flow rate

$\mathrm{ml}$ mole flow rate

\section{REFERENCES}

(1) Kang, Y.; Yang, Q.; Bartocci, P.; Wei, H.; Liu, S. S.; Wu, Z.; Zhou, H.; Yang, H.; Fantozzi, F.; Chen, H. Bioenergy in China: Evaluation of Domestic Biomass Resources and the Associated Greenhouse Gas Mitigation Potentials. Renewable Sustainable Energy Rev. 2020, 127, 109842

(2) Feng, F.; Song, G.; Shen, L.; Xiao, J. Environmental Benefits Analysis Based on Life Cycle Assessment of Rice Straw-Based Synthetic Natural Gas in China. Energy 2017, 139, 341-349.

(3) Mao, C.; Feng, Y.; Wang, X.; Ren, G. Review on Research Achievements of Biogas from Anaerobic Digestion. Renewable Sustainable Energy Rev. 2015, 45, 540-555.

(4) Kopyscinski, J.; Schildhauer, T. J.; Biollaz, S. M. A. Production of Synthetic Natural Gas (SNG) from Coal and Dry Biomass-A Technology Review from 1950 to 2009 . Fuel 2010, 89, 1763-1783.

(5) Tremel, A.; Gaderer, M.; Spliethoff, H. Small-Scale Production of Synthetic Natural Gas by Allothermal Biomass Gasification. Int. J. Energy Res. 2013, 37, 1318-1330.

(6) Sikarwar, V. S.; Zhao, M.; Fennell, P. S.; Shah, N.; Anthony, E. J. Progress in Biofuel Production from Gasification. Prog. Energy Combust. Sci. 2017, 61, 189-248.

(7) Zhao, L.; Yang, Y.; Zhou, H.; Que, Z.; Pan, Y. Ethanol Decomposition in Supercritical Water: An Operating Parametric Experimental and Kinetic Study. BioResources 2020, 15, 8515-8528.

(8) Song, G.; Zhao, L.; Zhao, H.; Xiao, J.; Wang, H.; Guo, S. Design and Assessment of a Novel Cogeneration Process of Synthetic Natural Gas and Char via Biomass Pyrolysis-Coupled Hydrothermal Gasi Fi Cation. Ind. Eng. Chem. Res. 2020, 59, 22205-22214.

(9) Haiduc, A. G.; Brandenberger, M.; Suquet, S.; Vogel, F.; BernierLatmani, R.; Ludwig, C. SunCHem: An Integrated Process for the Hydrothermal Production of Methane from Microalgae and $\mathrm{CO} 2$ Mitigation. J. Appl. Phycol. 2009, 21, 529-541.

(10) Zhou, H.; Zhao, L.; Fu, X.; Zhu, Y.; Pan, Y. Effects of Typical Alkaline Earth Metal Salts on Cellulose Torrefaction: Solid Products and Thermal Gravimetric Analysis. BioResources 2020, 15, 16781691

(11) Bailera, M.; Lisbona, P.; Romeo, L. M.; Espatolero, S. Power to Gas Projects Review: Lab, Pilot and Demo Plants for Storing Renewable Energy and CO2. Renewable Sustainable Energy Rev. 2017, 69, 292-312.

(12) Barbuzza, E.; Buceti, G.; Pozio, A.; Santarelli, M.; Tosti, S. Gasification of Wood Biomass with Renewable Hydrogen for the Production of Synthetic Natural Gas. Fuel 2019, 242, 520-531.

(13) Di Salvo, M.; Wei, M. Synthesis of Natural Gas from Thermochemical and Power-to-Gas Pathways for Industrial Sector Decarbonization in California. Energy 2019, 182, 1250-1264.

(14) Mesfun, S.; Lundgren, J.; Toffolo, A.; Lindbergh, G.; Lagergren, C.; Engvall, K. Integration of an Electrolysis Unit for Producer Gas Conditioning in a Bio-Synthetic Natural Gas Plant. J. Energy Resour. Technol. 2019, 141, 1-12.

(15) Menin, L.; Vakalis, S.; Benedetti, V.; Patuzzi, F.; Baratieri, M. Techno-Economic Assessment of an Integrated Biomass Gasification, Electrolysis, and Syngas Biomethanation Process. Biomass Convers. Biorefin. 2021, 11, 445-459. 
(16) Gassner, M.; Maréchal, F. Thermo-Economic Optimisation of the Integration of Electrolysis in Synthetic Natural Gas Production from Wood. Energy 2008, 33, 189-198.

(17) Gassner, M.; Maréchal, F. Thermo-Economic Process Model for Thermochemical Production of Synthetic Natural Gas (SNG) from Lignocellulosic Biomass. Biomass Bioenergy 2009, 33, 15871604.

(18) Wang, Z.; He, T.; Qin, J.; Wu, J.; Li, J.; Zi, Z.; Liu, G.; Wu, J.; Sun, L. Gasification of Biomass with Oxygen-Enriched Air in a Pilot Scale Two-Stage Gasifier. Fuel 2015, 150, 386-393.

(19) Li, Q.; Song, G.; Xiao, J.; Sun, T.; Yang, K. Exergy Analysis of Biomass Staged-Gasification for Hydrogen-Rich Syngas. Int. J. Hydrogen Energy 2019, 44, 2569-2579.

(20) Juraščík, M.; Sues, A.; Ptasinski, K. J. Exergetic Evaluation and Improvement of Biomass-to-Synthetic Natural Gas Conversion. Energy Environ. Sci. 2009, 2, 791-801.

(21) Prussi, M.; Padella, M.; Conton, M.; Postma, E. D.; Lonza, L. Review of Technologies for Biomethane Production and Assessment of Eu Transport Share in 2030. J. Cleaner Prod. 2019, 222, 565-572.

(22) Yuan, Y.; Liu, Z.; Zhao, L.; Luo, J.; Tang, S.; Zhang, Y. Analysis on the Development Status of Biomass Biogas Project. Jiangsu Agric. Sci. 2021, 49, 28-33.

(23) Song, G.; Xiao, J.; Yu, Y.; Shen, L. A Techno-Economic Assessment of SNG Production from Agriculture Residuals in China. Energy Sources, Part B 2016, 11, 465-471.

(24) Song, G.; Xiao, J.; Zhao, H.; Shen, L. A Unified Correlation for Estimating Specific Chemical Exergy of Solid and Liquid Fuels. Energy 2012, 40, 164-173.

(25) Han, Y. Development Status of Biogas Purification in China. In Proceedings of 10th Symposium on China Gas Operation and Safety: Shanghai, 2019; pp 510-515.

(26) Song, G.; Feng, F.; Xiao, J.; Shen, L. Technical Assessment of Synthetic Natural Gas (SNG) Production from Agriculture Residuals. J. Therm. Sci. 2013, 22, 359-365.

(27) Schmidt, O.; Gambhir, A.; Staffell, I.; Hawkes, A.; Nelson, J.; Few, S. Future Cost and Performance of Water Electrolysis: An Expert Elicitation Study. Int. J. Hydrogen Energy 2017, 42, 3047030492.

(28) Dawood, F.; Anda, M.; Shafiullah, G. M. Hydrogen Production for Energy: An Overview. Int. J. Hydrogen Energy 2020, 45, 38473869.

(29) Seemann, M. C.; Schildhauer, T. J.; Biollaz, S. M. A. Fluidized Bed Methanation of Wood-Derived Producer Gas for the Production of Synthetic Natural Gas. Ind. Eng. Chem. Res. 2010, 49, 7034-7038.

(30) Gu, H.; Song, G.; Xiao, J.; Zhao, H.; Shen, L. Thermodynamic Analysis of the Biomass-to-Synthetic Natural Gas Using Chemical Looping Technology with $\mathrm{CaO}$ Sorbent. Energy Fuels 2013, 27, 4695-4704.

(31) Barisano, D.; Canneto, G.; Nanna, F.; Alvino, E.; Pinto, G.; Villone, A.; Carnevale, M.; Valerio, V.; Battafarano, A.; Braccio, G. Steam/Oxygen Biomass Gasification at Pilot Scale in an Internally Circulating Bubbling Fluidized Bed Reactor. Fuel Process. Technol. 2016, 141, 74-81.

(32) Sarić, M.; Dijkstra, J. W.; Walspurger, S. Power-to-Gas Coupling to Biomethane Production: A Feasibility Study. In Proceedings of the 13th International Conference on Polygeneration Strategies; Vienna, Austria, 2013.

(33) Kumar, L. R.; Zhang, X.; Kaur, R.; Yellapu, S. K.; Tyagi, R. D.; Drogui, P. Techno-Economic Analysis for Extracellular-Polymeric Substances (EPS) Production Using Activated Sludge Fortified with Crude Glycerol as Substrate and Its Application in Leachate Treatment. Bioresour. Technol. 2020, 303, 122954.

(34) Li, G.; Chang, Y.; Chen, L.; Liu, F.; Ma, S.; Wang, F.; Zhang, Y. Process Design and Economic Assessment of Butanol Production from Lignocellulosic Biomass via Chemical Looping Gasification. Bioresour. Technol. 2020, 316, 123906.

(35) Bu, S.; Xiao, J.; Shen, L.; Li, H.; Song, G.; Du, Y. Integrated Performance Evaluation of Dimethyl Ether from Biomass. Proc. Chin. Soc. Electr. Eng. 2014, 15, 3332-3340.
(36) Götz, M.; Lefebvre, J.; Mörs, F.; McDaniel Koch, A.; Graf, F.; Bajohr, S.; Reimert, R.; Kolb, T. Renewable Power-to-Gas: A Technological and Economic Review. Renewable Energy 2016, 85, $1371-1390$

(37) Li, D.; Lan, N. Record of construction of Lianyuan Steel VPSA oxygen production project by Beijing Peking University Pioneer. h t t p : / / w w w. c c i n. com.cn / d e t a i l /

f105eee190dc0ac2bb78755eb95864a7 (accessed April 10, 2021).

(38) Gu, H.; Tang, Y.; Yao, J.; Chen, F. Study on Biomass Gasification under Various Operating Conditions. J. Energy Inst. 2019, 92, 1329-1336.

(39) Bonilla, J.; Gordillo, G.; Cantor, C. Experimental Gasification of Coffee Husk Using Pure Oxygen-Steam Blends. Front. Energy Res. 2019, 7, 1-11.

(40) GB/T13611-2018. Classification and Basic Characteristics of City Gas; Chinese National Technical Standard, 2018.

(41) Gupta, S. K.; Mittal, M. Effect of Biogas Composition Variations on Engine Characteristics Including Operational Limits of a Spark-Ignition Engine. J. Eng. Gas Turbines Power 2019, 141, 1-8.

(42) Vitasari, C. R.; Jurascik, M.; Ptasinski, K. J. Exergy Analysis of Biomass-to-Synthetic Natural Gas (SNG) Process via Indirect Gasification of Various Biomass Feedstock. Energy 2011, 36, 38253837.

(43) Zhang, B.; Zhang, L.; Yang, Z.; He, Z. An Experiment Study of Biomass Steam Gasification over NiO/Dolomite for Hydrogen-Rich Gas Production. Int. J. Hydrogen Energy 2017, 42, 76-85.

(44) Zhang, Z.; Pang, S. Experimental Investigation of Tar Formation and Producer Gas Composition in Biomass Steam Gasification in a $100 \mathrm{KW}$ Dual Fluidised Bed Gasifier. Renewable Energy 2019, 132, 416-424.

(45) GB/T33445-2016. Coal-Based Synthetic Natural Gas; Chinese National Technical Standard, 2016.

(46) Jurašč́k, M.; Sues, A.; Ptasinski, K. J. Exergy Analysis of Synthetic Natural Gas Production Method from Biomass. Energy 2010, 35, 880-888.

(47) Field, K. Tesla Model 3 Battery Pack \& Battery Cell Teardown Highlights Performance Improvements. https://cleantechnica.com/ 2019/01/28/tesla-model-3-battery-pack-cell-teardown-highlightsperformance-improvements/ (accessed May 10, 2021).

(48) Wang, X.; Xiong, Y. Study on Influencing Factors of Farmers' Green Energy Consumption Behavior: A Comparative Analysis of Household Biogas and Medium \& Large-Scale Biogas User. J. Nanjing Tech Univ., Sci. Ed. 2018, 17, 69-78.

(49) Li, Q.; Song, G.; Xiao, J.; Hao, J.; Li, H.; Yuan, Y. Exergetic Life Cycle Assessment of Hydrogen Production from Biomass StagedGasification. Energy 2020, 190, 116416.

(50) Feng, F.; Song, G. H.; Shen, L. H.; Xiao, J. Energy Efficiency Analysis of Biomass-Based Synthetic Natural Gas Production Process Using Interconnected Fluidized Beds and Fluidized Bed Methanation Reactor. Clean Technol. Environ. Policy 2016, 18, 965-971.

(51) Haydary, J. Modelling of Two Stage Gasification of Waste Biomass. Chem. Eng. Trans. 2017, 61, 1465-1470. 